\title{
Evidencias, aspectos materiales y técnicas constructivas del recinto amurallado de la madina Buryāna (Burriana, Castellón)
}

\section{Evidence, material aspects and construction techniques of the walled enclosure of madina Buryāna (Burriana, Castellón)}

\author{
Josep Benedito Nuez ${ }^{1}$ \\ Universitat Jaume I de Castellón \\ José Manuel Melchor Monserrat² \\ Museo Arqueológico de Burriana
}

\section{RESUMEN}

La ciudad de Burriana se localiza frente a la costa del mar Mediterráneo, muy próxima al río Anna, a los pies de las principales vías de comunicación que vertebran el levante peninsular, con puerto marítimo y sobre un terreno fértil. Su localización la convierte en un importante enclave defensivo relacionado con la protección del paso hacia Murbātir (Sagunto) desde el río Millars. Pero la fuerte transformación urbanística que sufre desde la segunda mitad del siglo XIX ha enmascarado su trazado fortificado. A partir del trabajo que aquí se presenta se pretende recuperar información de la ciudad en época islámica, sobre todo lo concerniente a su sistema de fortificación y las transformaciones que esta ha ido sufriendo. Se presenta también un análisis de las técnicas constructivas. Una vez analizados los datos, se proyecta una restitución del trazado de la muralla, torres y portales.

Palabras clave: Al-Ándalus; murallas; puertas de fortificaciones; albarranas; tapial; mampostería.

\begin{abstract}
The city of Burriana is located in the Mediterranean coast by the river Anna. Near the main communication routes that go across the peninsular east, it has been provided with a seaport and is placed on fertile ground. Its location turned it into an important defensive enclave probably devoted to the protection of the passage that extended from the river Millars to Murbātir (Sagunto). However, due to the strong urban transformation occurred since the second half of the nineteenth century, its fortified layout has been disguised. The current study aims at retrieving information about the city during the Islamic period, especially as regards its fortification system and subsequent transformations. An analysis of the construction techniques is also presented. After examining these data, it is proposed a restitution of the layout of the wall, towers and portals.
\end{abstract}

Key words: Al-Andalus; walls; fortified gateway; albarrana tower; rammed earth wall; masonry.

Recibido: 05-02-2020. Aceptado: 11-06-2020. Publicado online: 18-11-2020

Cómo citar este artículo / Citation

Benedito Nuez, J. y Melchor Monserrat, J. M. 2020: "Evidencias, aspectos materiales y técnicas constructivas del recinto amurallado de la madīna Buryāna (Burriana, Castellón)", Arqueología de la Arquitectura, 17: e097. https://doi.org/10.3989/arq.arqt.2020.006

Copyright: (c) CSIC, 2020. (c) UPV/EHU Press, 2020. Este es un artículo de acceso abierto distribuido bajo los términos de la licencia de uso y distribución Creative Commons Reconocimiento 4.0 Internacional (CC BY 4.0).

\footnotetext{
josep.benedito@uji.es / ORCID iD: http;//orcid.org/0000-0002-1095-6079

2 arqueologo@burriana.es / ORCID iD: http://orcid.org/0000-0002-8834-4240
} 


\section{INTRODUCCIÓN}

En este artículo nos centraremos en el análisis de los restos arquitectónicos de la muralla de la madinna Buryāna (Burriana). Las distintas intervenciones arqueológicas que se han realizado en el casco urbano durante más de cuarenta años han permitido documentar las cimentaciones, parte del alzado del lienzo murario y algunas de las torres. Se trata sobre todo de excavaciones de urgencia y que por tanto no fueron planificadas según criterios rigurosamente científicos, por lo que la información que proporcionan en algunos casos contiene algunos sesgos que comentaremos. Por otra parte, en otras actuaciones de carácter no arqueológico se pudo distinguir la superposición de edificios al paramento de la muralla, a la vez que alguna de las reformas o reparaciones que se llevaron a cabo antes de ser parcialmente derruida. A lo largo de este trabajo trataremos un aspecto de la construcción de la muralla poco conocido, como es el análisis de sus técnicas constructivas y la descripción de algunas de las prácticas reparadoras que se utilizaron para dar solidez a la fortificación. De ello se desprende la importancia de usar una metodología arqueológica adecuada con el fin de diferenciar las técnicas y materiales utilizados en cada uno de los aparejos o fábricas.

Al respecto de la madina Buryāna, las referencias en los documentos históricos son prácticamente inexistentes. Los textos árabes y las referencias cristianas contemporáneas a la conquista solo permiten que conozcamos de forma concisa cómo se organizaba la geografía histórica de esta parte de la costa levantina, emplazada en un territorio que se caracteriza por la presencia de otras ciudades importantes como Unda (Onda) y Murbātir (Sagunto). Sabemos que lindaba con el territorio de esta última por el sur, mientras que lo hacía con Unda por el oeste. Al este limitaba con el mar Mediterráneo; sin embargo, no se han encontrado referencias históricas sobre el límite norte.

Al-Rāzī, que vivió en el siglo X, cita el distrito o término de Burriana (Lévi Provençal 1953: 72). Al-Idrīsī hace lo propio en el siglo XII y describe también su puerto, marsà Buryāna (Edrîsî 1968; Al-Idrīsī 1989). Nuevas referencias sobre el puerto (ad portum maris Burriane) aparecen en las donaciones del rey Jaime I (De María 1933: 28). Ibn al-Abbār (m. 1260) se refiere a Burriana como centro de un 'amal (Guichard 1987: 71). Por otra parte, los testimonios arqueológicos y también los textos han constatado la ocupación del entorno rural alrededor de la madīna. Las excavaciones han confirmado la existencia de restos asimilados por las fuentes escritas tradicionalmente a qurà, mientras que la documentación de época cristiana completa la información que tenemos sobre la organización de este tipo de poblamiento diseminado (Melchor 2011). Durante muchos años, la tendencia ha sido la de no considerar otros tipos de asentamientos en el campo que no fueran alquerías (qurà), sin explicar exactamente a qué nos estábamos refiriendo. En castellano es una palabra ambigua que hace alusión a un lugar habitado en la zona rural, sin llegar a describir los variados tipos de propiedades fiscales. Entendemos, por tanto, que en el caso concreto de Burriana algunas de las comunidades rurales tal vez estarían integradas en pequeñas qurà dependientes de la madīna Buryāna, pero si seguimos considerando el mundo rural islámico desde el esquema simple de madīna y qurà, apenas se podrán entender otros matices económicos y la jerarquización administrativa de este distrito, así como el tipo de relaciones que existirían entre los diferentes lugares que lo componían, como por ejemplo la existencia de granjas $(r a h \bar{a} l)$, fincas dedicadas a la explotación del campo (mâyāšir) o haciendas privadas (riyāọ); y aunque resulta difícil conocer las verdaderas características del poblamiento que existiría en esta época, lo cierto es que en estas tierras la sociedad se encontraba en un proceso continuo de ruralización. La información de que disponemos actualmente en Burriana es representativa, pero está llena de incógnitas por lo que debemos tratar los datos con cierta reserva a la hora de catalogar la realidad de estas tierras en época islámica.

Entre los textos destaca el Libre del Repartiment, la fuente contemporánea que se conoce para estudiar la repoblación de las tierras valencianas tras la conquista de Jaime I. Otra fuente es al-Himyarī (m. 1325), que utiliza textos andalusíes anteriores a su tiempo; señala que "es una ciudad magnífica, poblada, con abundantes frutos, árboles y viñas" (Labarta et al. 2011: 64).

Las fuentes cristianas tampoco mencionan la extensión del término de Burriana. La primera referencia aparece en el Cantar del Mio Cid (Guichard 1987: 71). Sabemos que, con la caída de Tortosa, en el año 1148, se convirtió en cabeza de circunscripción militar, tal y como aparece en un texto del Archivo de la Corona de Aragón de la época de Ramón Berenguer IV que cita a un alcaid o jefe militar de Burriana (Guichard 2001: 243-244). La conquista cristiana se produjo en 1233 y la Carta-Pobla se le concedió tres meses después de la conquista, en noviembre, aunque apenas dos años más tarde se hizo necesario redactar una segunda (García 
1989: 14, 33). Entre los documentos de donaciones de Jaime I aparecen referencias sobre "Castillione Burrianae" (Ramón 2001: 95), "Castelló del camp de Borriana" (Castellón), Nules y Almazora (De María 1933: $253,70,120)$ que debieron formar parte del antiguo 'amal de Burriana, junto a datos concretos sobre la fundación de Vila-real (De María 1933: 253), que sabemos que fue segregada de buena parte de la zona occidental del antiguo término municipal de Burriana.

En el siglo XIII Burriana va a seguir ejerciendo la función de puntal estratégico durante el proceso de conquista, tanto en el control del paso para poder acceder a toda La Plana, territorio de Sagunto y Valencia, como desde el punto de vista comercial y agrícola. Conformará un extenso territorio al igual que otras plazas fuertes de la zona. La Corona de Aragón dio prioridad defensiva y administrativa a este distrito. La caída de Burriana arrastraría el resto del territorio hasta Sagunto y también parte del territorio norte de Castellón, pues quedó su retaguardia descubierta (Felip 1991). Poco después la acción repobladora cristiana aseguró la posesión y defensa del territorio instalando en esta villa nuevos habitantes y creando otras como Nules, Castellón y la citada Vila-real.

\section{TESTIMONIOS DE LAS FUENTES HISTÓRICAS SOBRE EL RECINTO FORTIFICADO}

El testimonio más antiguo se halla en la Chronica de la inclita y coronada ciudad de Valencia y de su reino, una de las grandes crónicas del siglo XVI obra del cronista Rafael Martín de Viciana, natural de la villa de Burriana. Obra dividida en cuatro libros, la última parte del tercer libro ofrece una preciada compilación de información que profundiza en la descripción de la muralla (Fig. 1).

Está rodeada de muro y hecha en forma circular por espacio de CCLXX braçadas por el andén del muro. Tiene quarenta torres terraplenas, dos gruesos baluartes, barbacana, fosso muy ancho y hondo, tres puertas en el muro muy fortificadas. El fosso se acostumbra de hendir de agua toda vez que quieren los del pueblo, donde se hace treynta palmos de hondo y ochenta de ancho, consérvase largos días en plenitud de una vez que le hinchan, y no tiene forma de vaziarse por sangredero, ni la tierra se puede minar, porque siendo el fosso de agua, del suelo del fosso hasta el agua manantial hay de espeso de tierra más de seys hasta ocho palmos (Viciana 1564).
Viciana en su crónica describe que presenció los hechos de las guerras de las Germanías valencianas, acontecimiento al que le dedicó un extenso libro. Transcribió en la crónica el contenido de una misiva en la que se pone de manifiesto los "muchos travesses y reparos" que tuvieron que realizarse en el espacio del antemuro o acitara, aunque apenas permite conocer detalles importantes sobre la obra de defensa.

... tiene la cerca muy gruesa, con tres baluartes y quarenta torres terraplenas y barbacana que la ciñe toda, con muchos travesses y reparos en ella después ay un fosso con diez braçadas de ancho y quatro braçadas de ondo (unos $20 \mathrm{~m}$. de ancho por $8 \mathrm{~m}$. de profundidad), este fosso está lleno de agua y le puede conservar mucho tiempo lleno, porque tiene mucha agua en una acequia junto al foso es tierra bastecida de todas cosas necesarias para mantenimiento de la gente que en ella se retruxere para largos días, y aunque es redonda es pequeña, que no tiene más de CCXX bragadas de contorno, que por tener todo lo suzodicho está en buena defensa (Mesado 1991).

Por su parte, en el Llibre dels Fets se describe el antemuro cuando se relata la retirada de los musulmanes hacia la ciudad: "e metem los pres la barbacana a dins [...] entraren-sen per la barbacana".

El análisis de la fábrica de la fortificación, materiales y ejecución ha suscitado escasa atención en el ámbito de los estudios sobre la historia de la localidad. A este respecto, no se sabe con certeza cuándo se llevaron a cabo los trabajos del derribo generalizado de la fortificación, que comenzarían probablemente con el decreto de Nueva Planta promulgado por Felipe VI y finalizarían a finales del siglo XIX con el derrumbamiento del Portal de Onda.

Roca y Alcaide (1932) deja constancia en su obra de una valiosa información sobre la muralla, el callejón interno de $4 \mathrm{~m}$ para los defensores de la plaza, el lienzo de muralla que tenía sentido rectilíneo saliendo por donde estuvo el Portal de Tortosa, los dos bastiones que se sitúan a mano izquierda, uno en el inmueble número 20 de la calle de los Desamparados y otro contiguo a la sacristía de la iglesia del Salvador. En este emplazamiento, junto a la Capilla de la Comunión, permanecía en pie en 1964 un trozo de fortificación de "pura arcilla apelmazada entre alguna lechada de cal” (Mesado 1991) (Fig. 2). Respecto a las torres macizas de la plaza fuerte que describen las fuentes, una de ellas ha perdurado en los patios traseros de los inmuebles 26 y 28 de la calle San Pascual, que describiremos con detalle en el siguiente apartado (Fig. 3). 


 CDe la pilla oe Buriana.}

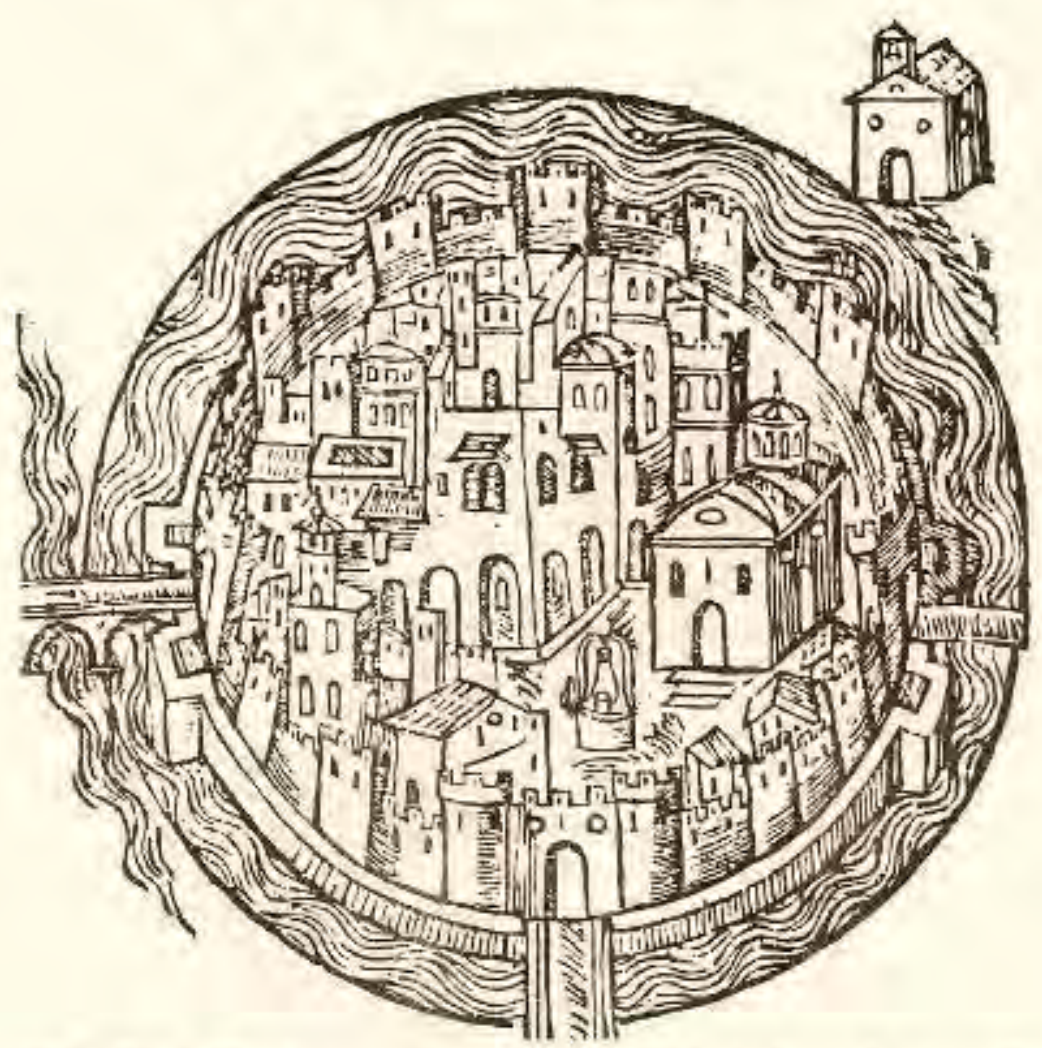

(1)

Ivflla de IBurtana es vina be las mas celebradas vilias ơ to do el repno be Clalencia/pozel venturoloconquiftadoz rep oó 马apme en fu cbronpca:t porende en las predicactones oe las percelebres fieftas be lant 3 ozgep be rant Diongtio/ quece lebra la inclita 2 coronads cindad oe Us lenciaipor memoria be la gloriof́a victos ria que nueftro felice rep alcąço $\delta$ la mén ma ciudad:fe baze de .Juriana tantas ve 3 es z a cada paffo mencion. Mo es por cierto fin caulg grande. 7Dozque el num: ca vencido rep/antes oe començar lacō. quifta bel repno fue bien infomado: 2 af filo conidero $\tau$ lo confirmo:queptimes ro oeus ganar Iburiana por fer puerta rcaufapincipal para la conquifa 8 \&a lenciaŕegun lo trata el rep en fu cbionta: ca. Y affiel rep partio cō fi exercito $\tau$ paf́ Tandopos Fertca bonde tumo algunos rencuentros con los 29 garenos/marcbo para IBurtanal la qual le parefcio mup fiserte poz tener muro ibarbacana/ z fo [ for mus baftelcidas piouifiones ir mup lletra oe gentes/por fer lo fuerter cabeçs principal be la comarca: $z$ alicntada en campo bermolo z verde/plantado be of: uer 108 generos oe arboles: 2 por efta cats fa los 2ugarenos en 2irauigo la nombza uarv GEetina albadra/cono fi orteran' cindad perde. Eltenombte le pufieron ellosirorqute el sntiguo $\tau$ painierol z elâ bog tiene bofido e es Towiand que 26 


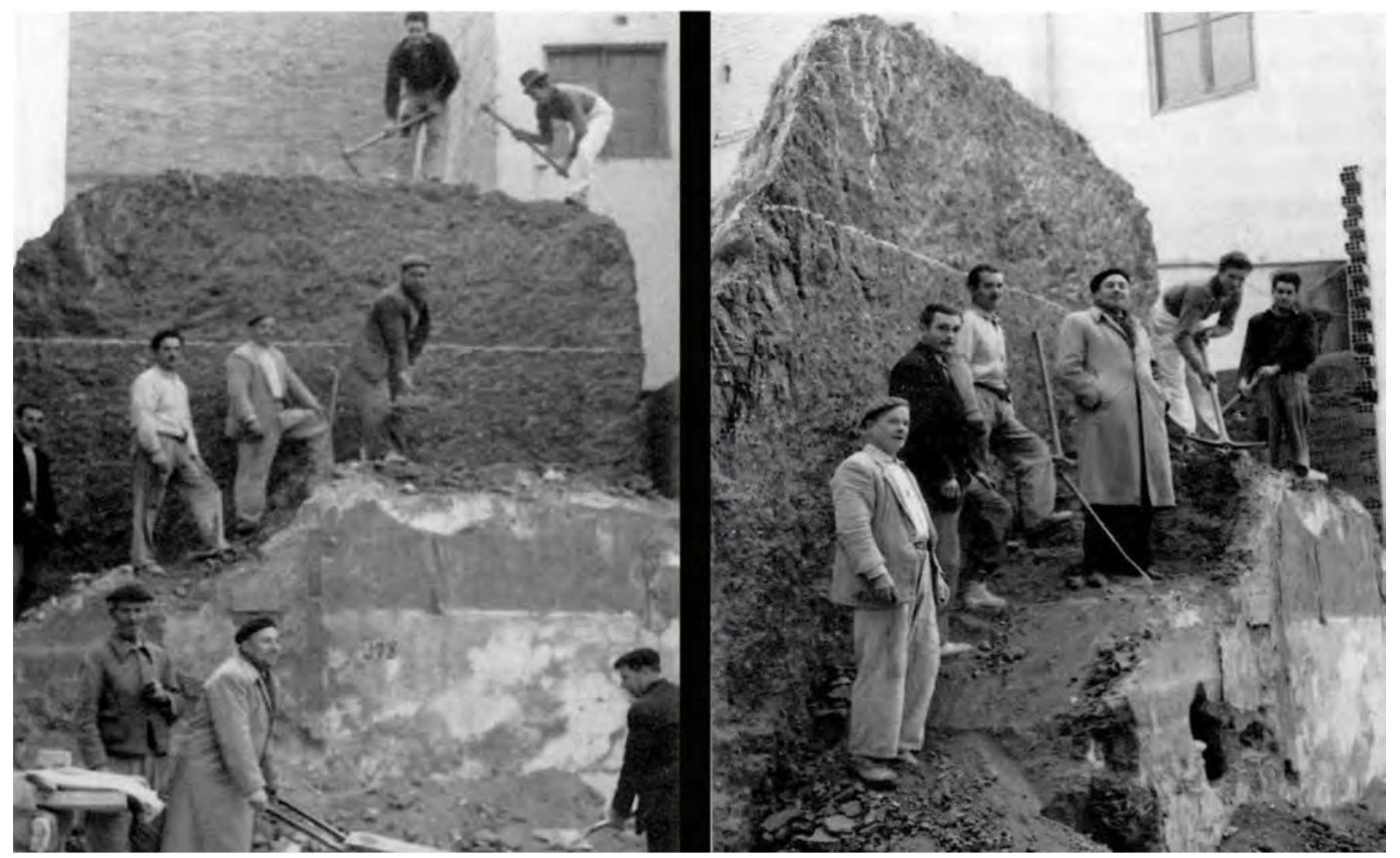

Figura 2. Trabajos de derribo de la muralla realizados junto a la Capilla de la Comunión en la década de 1950. Fuente: Mesado (1991: 74).

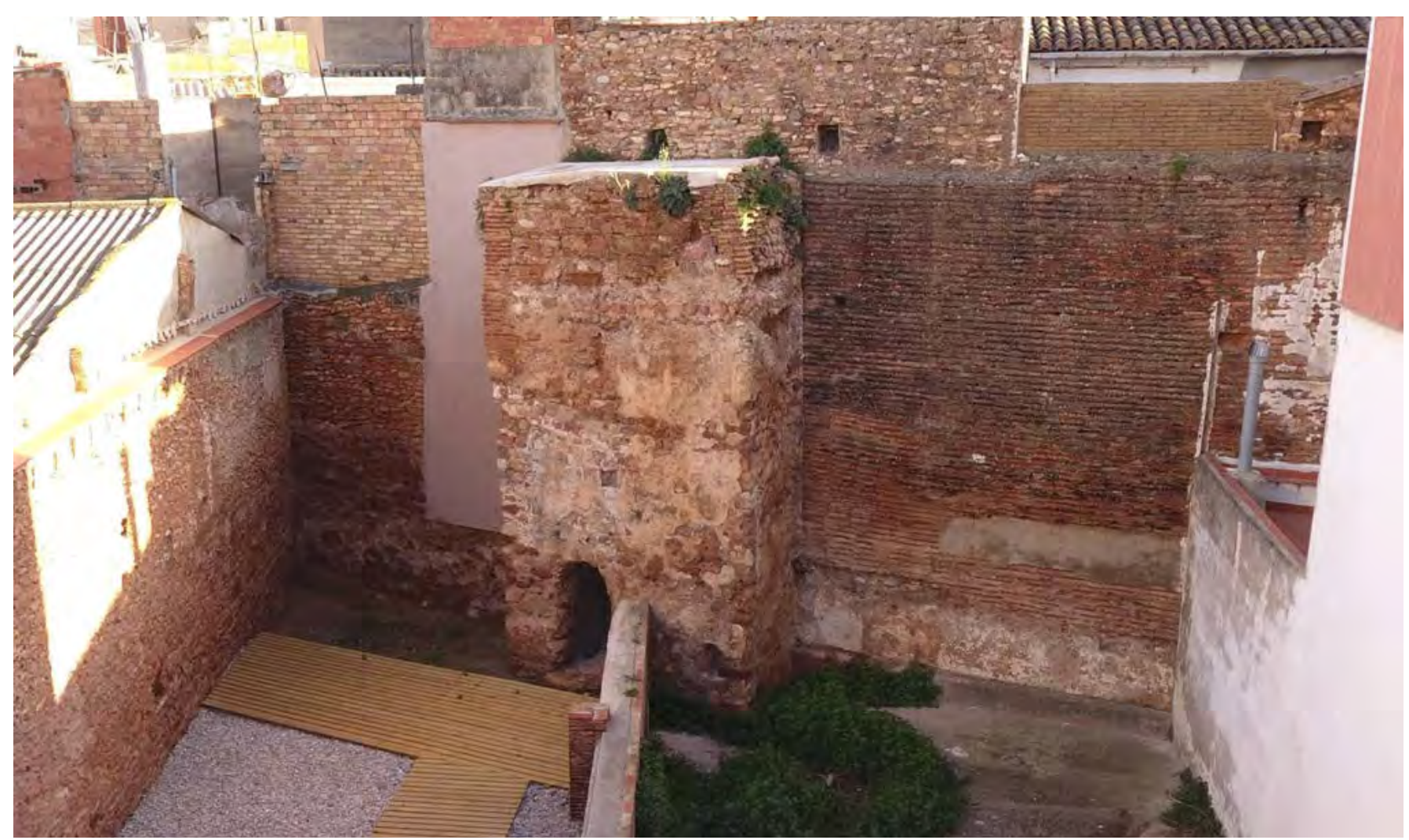

Figura 3. Torre y paramento exterior de la muralla de la calle San Pascual, 26-28. A la izquierda, solar puesto en valor por el Ayuntamiento de Burriana. Fotografía: Museo Arqueológico de Burriana. 
DE LA MADĪNA BURYĀNA (BURRIANA, CASTELLÓN)

Por su parte, N. Mesado (1991) describe que durante la primera mitad del siglo XX se conservaba parte del perímetro oeste del muro con almenas, pero que fue derribado para aumentar el tamaño del inmueble de Talleres Tormo. Este sector debía corresponder al tramo denominado de Assalit. En 1988, en el interior de este edificio, todavía existía parte de la muralla cuando se derribó para construir viviendas (Fig. 4), sin embargo, durante los trabajos no se llevó a cabo ninguna intervención arqueológica.

\section{LOS RESTOS CONSERVADOS}

En la actualidad, a pesar de que el conocimiento del tema es parcial, estamos en condiciones de proponer una restitución del recorrido del sistema defensivo de época islámica (Fig. 5). En este sentido, vamos a presentar los trabajos más significativos, algunos de los cuales se iniciaron en la década de 1980. En general, las descripciones están basadas en el registro arqueológico y en los materiales que aparecen en los niveles de construcción o abandono asociados a la arquitectura. El interés por la puesta en valor y conservación de algunos tramos de esta fortificación por parte del ayuntamiento de esta localidad ha motivado la ejecución de trabajos muy interesantes, si

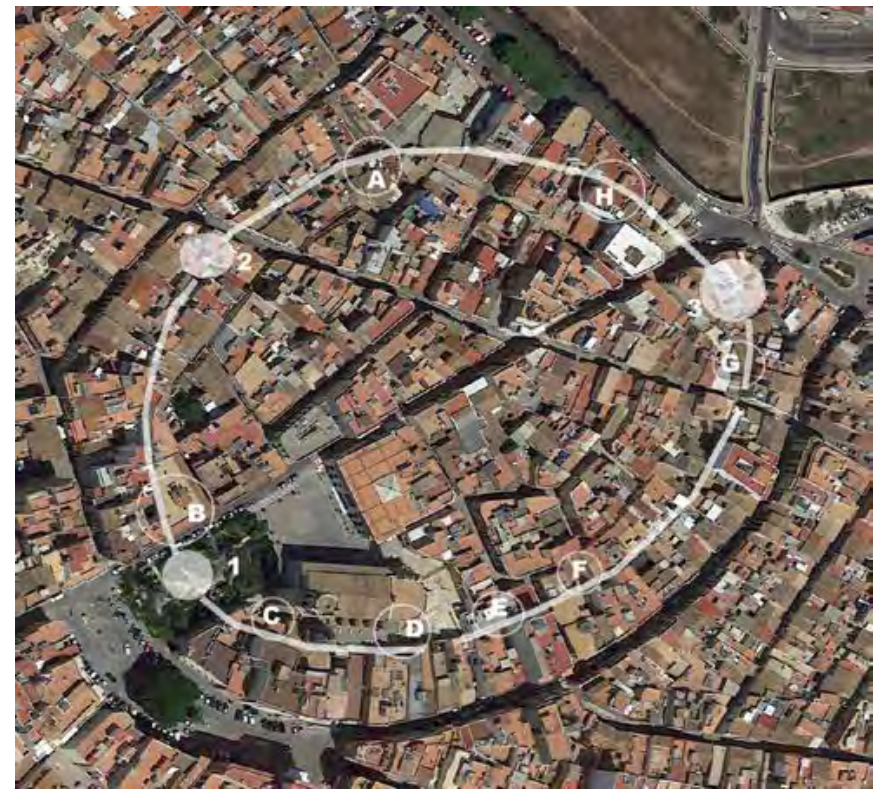

Figura 5. Alineación de la muralla de Burriana, con el espacio que ocuparían los portales y hallazgos citados en el texto. (1) Portal de Valencia; (2) Portal de Onda y (3) Portal de Tortosa; (A) Torre San Pascual; (B) Calle Mayor, 26; (C) Muralla derribada en la década de 1950; (D) Torre del Racó de I'Abadia; (E) Nueva Casa Abadía; (F) Calle Sant Joan, 16; (G) Torre calle Zaragoza; $(\mathrm{H})$ Talleres Tormo. El Portal de Onda y el Portal de Tortosa se sitúan sobre la imagen aérea de la población tomando en consideración las características urbanas de la ciudad y no por contar con restos materiales. Infografía de los autores sobre sobre fotografía aérea Google Earth 2018.

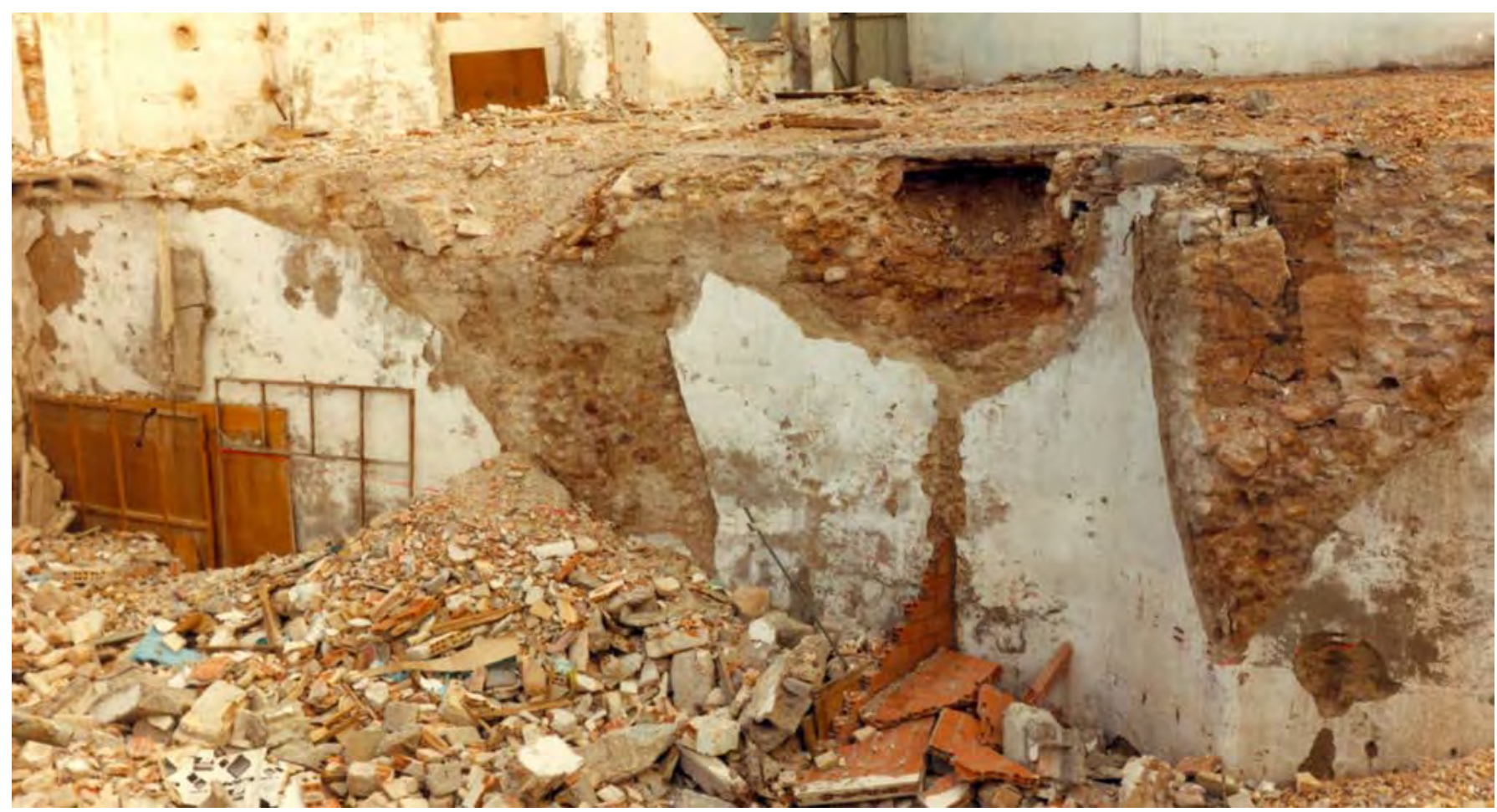

Figura 4. Trabajos de derribo del inmueble de Talleres Tormo que se Ilevaron a cabo sin vigilancia arqueológica. Fotografía: autores. 
bien todavía quedan algunas lagunas científicas por cubrir. A continuación, trataremos de definir detalladamente cada una de estas intervenciones.

P. Guichard y N. Mesado (1976) realizaron una serie de investigaciones en la localidad que en su momento marcaron las líneas de trabajo sobre la época andalusí porque en sus intervenciones definieron por primera vez una secuencia estratigráfica continuada. Desde entonces, las excavaciones que se han realizado en el marco de la arqueología medieval han sido muchas, aunque algunas de ellas todavía permanecen inéditas.

\subsection{Obras de la calle Mayor}

Estos trabajos revelaron la existencia de los primeros indicios de estructuras que coincidían con el muro defensivo. En 1967 la Compañía Telefónica Nacional de España abrió una zanja a lo largo del recorrido de la calle Mayor. N. Mesado, encargado en ese momento de dirigir el museo de la ciudad, describió que la extracción de tierras puso al descubierto los restos de una cimentación de mampostería de cantos de río que recorría de este a oeste la calle. El espesor de esta estructura arqueológica era de $0,75 \mathrm{~m}$ y junto a ella salió a la luz una estrecha franja de tierra de 1,90 $\mathrm{m}$ de anchura que siguiendo los textos de Roca y Alcaide (1932) interpretó como el andén del muro. La siguiente estructura documentada correspondía a los restos de la muralla elaborada con cantos de río, cal y tierra, de 4,40 m de espesor. Sin embargo, atendiendo a estas dimensiones, cabe la posibilidad de que este hallazgo pueda relacionarse con la base de una de las torres macizas que envolvían el recinto defensivo. Por último, se documentó un espacio de tierra de 3,20 m que apareció frente a la muralla y una cimentación de 1,20 m de espesor, elaborada con mampuesto de cal y cantos de río, que se identificó como una de las dos torres gemelas del Portal de Valencia (Mesado 1991), aunque tal vez pudiera relacionarse con el antemuro. También describe un espacio de 3,20 m que apareció limitado por una cimentación de mampostería de cal y cantos de río, que se interpretó como la berma que limitaba con el foso (vall), que tenía una anchura de $15,50 \mathrm{~m}$.

\subsection{Obras de remodelación de la plaza Mayor}

En el transcurso de los trabajos de remodelación urbanística de la plaza Mayor que se llevaron a cabo en 1986, junto la calle Mayor, salieron a la luz los restos del Portal de Valencia (Fig. 6). La cimentación apareció en el sector oriental de la plaza. La estructura tenía una luz de 3,30 por $1,70 \mathrm{~m}$, y la entrada una anchura de $1,85 \mathrm{~m}$ que correspondería al vano de la escalera de mano utilizada para alcanzar la zona de guardia del portal, junto a los matacanes y el adarve (Mesado 1991). En estas obras no se llevaron a cabo excavaciones arqueológicas, por lo que es muy escasa la información que se conserva relativa a los trabajos.

\subsection{Solar número 16 de la calle Sant Joan}

Los trabajos de excavación que se llevaron a cabo en el año 1988 en el solar número 16 de la calle Sant Joan, sacaron a la luz los restos de una cimentación que atravesaba el solar en dirección norte-sur y que apareció a una cota de profundidad de $0,55 \mathrm{~m}$. V. Verdegal, el arqueólogo encargado de realizar los trabajos, interpretó los restos como un muro interior que separaba el recinto de la fortificación de la ciudad (Verdegal 1989), lo que le llevó, por equivocación, a vaciar el tapial del interior de la muralla. El hallazgo correspondía en realidad al calicostrado del lienzo defensivo. A una profundidad de 1,44 m se localizó una alineación de cantos de río, circunstancia que impidió continuar los trabajos. Estos restos se pueden interpretar como la base de la cimentación de la muralla.

\subsection{Patio de la antigua Casa Abadía}

En el patio de la antigua Casa Abadía (Fig. 7, 2), la arqueóloga P. Ulloa realizó una excavación arqueológica en el año 1995 que sacó a la luz nuevos restos de la estructura defensiva. Respecto a la muralla, a $1,50 \mathrm{~m}$ de esta se localizó un murete de tapial de $14 \mathrm{~cm}$ de grosor y $60 \mathrm{~cm}$ de altura y un suelo de mortero asociado a él y situado a 1,4 $\mathrm{m}$ de profundidad, que se interpretó como un espacio abierto, tal vez ajardinado (Ulloa 2000). En realidad, como pudo comprobarse en las intervenciones que llevó a cabo el Servicio Municipal de Arqueología en este mismo ambiente en el año 2008, se trataba del calicostrado y tapial de la propia muralla por lo que, como en el ejemplo anterior, se había procedido erróneamente a excavar el encofrado de la muralla.

\subsection{Solar de la calle Mayor número 26 esquina con la calle Forn de la Vila número 2}

La excavación fue realizada por M. Claramonte, J. M. Melchor y J. Benedito en el año 2003 y permitió 


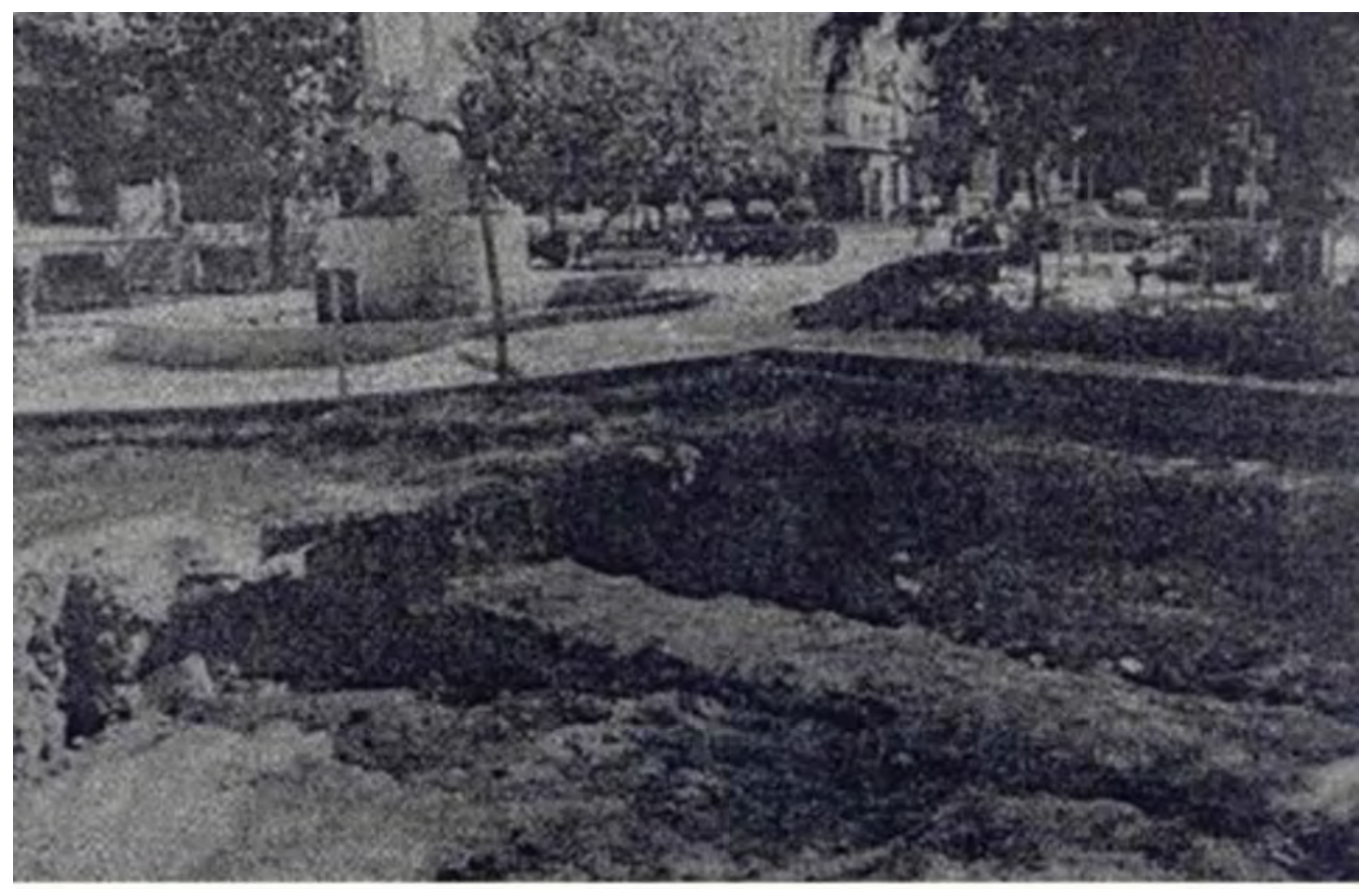

\section{PLANO DE SITUACION}
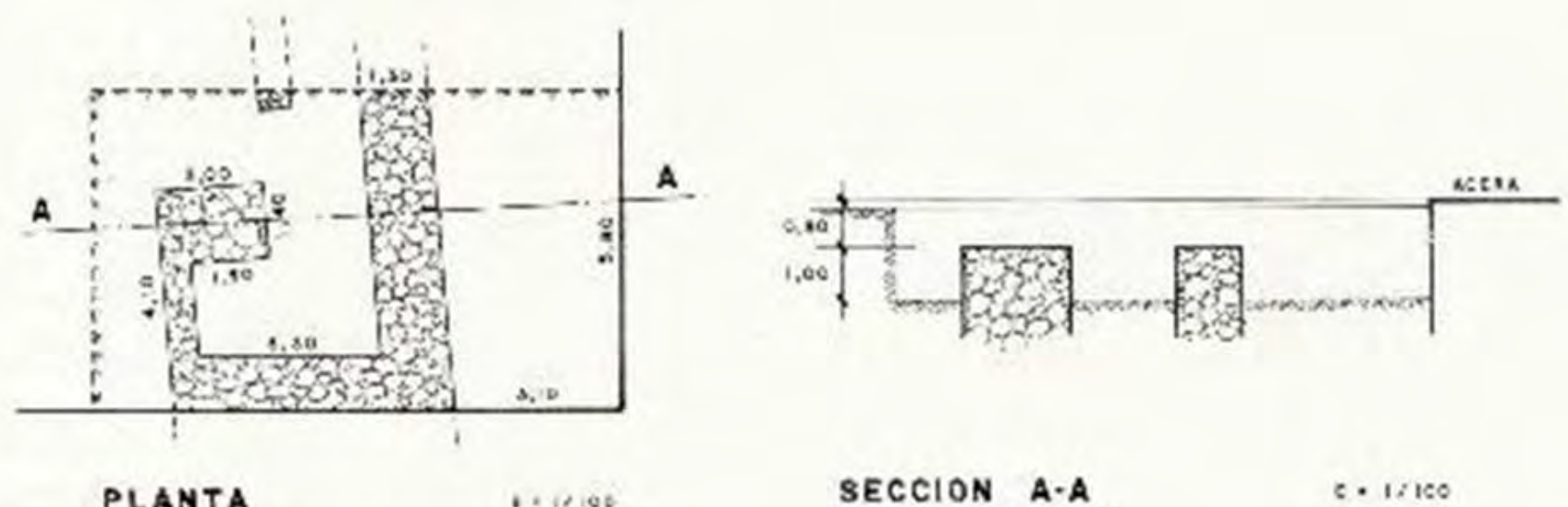

PLANTA

W inios

SECCION A-A

c. IZIGC

Figura 6. Fotografía con los restos de la fortificación descubiertos en la plaza Mayor. Planta y sección de los hallazgos. Fuente: Mesado (1991: 84). 

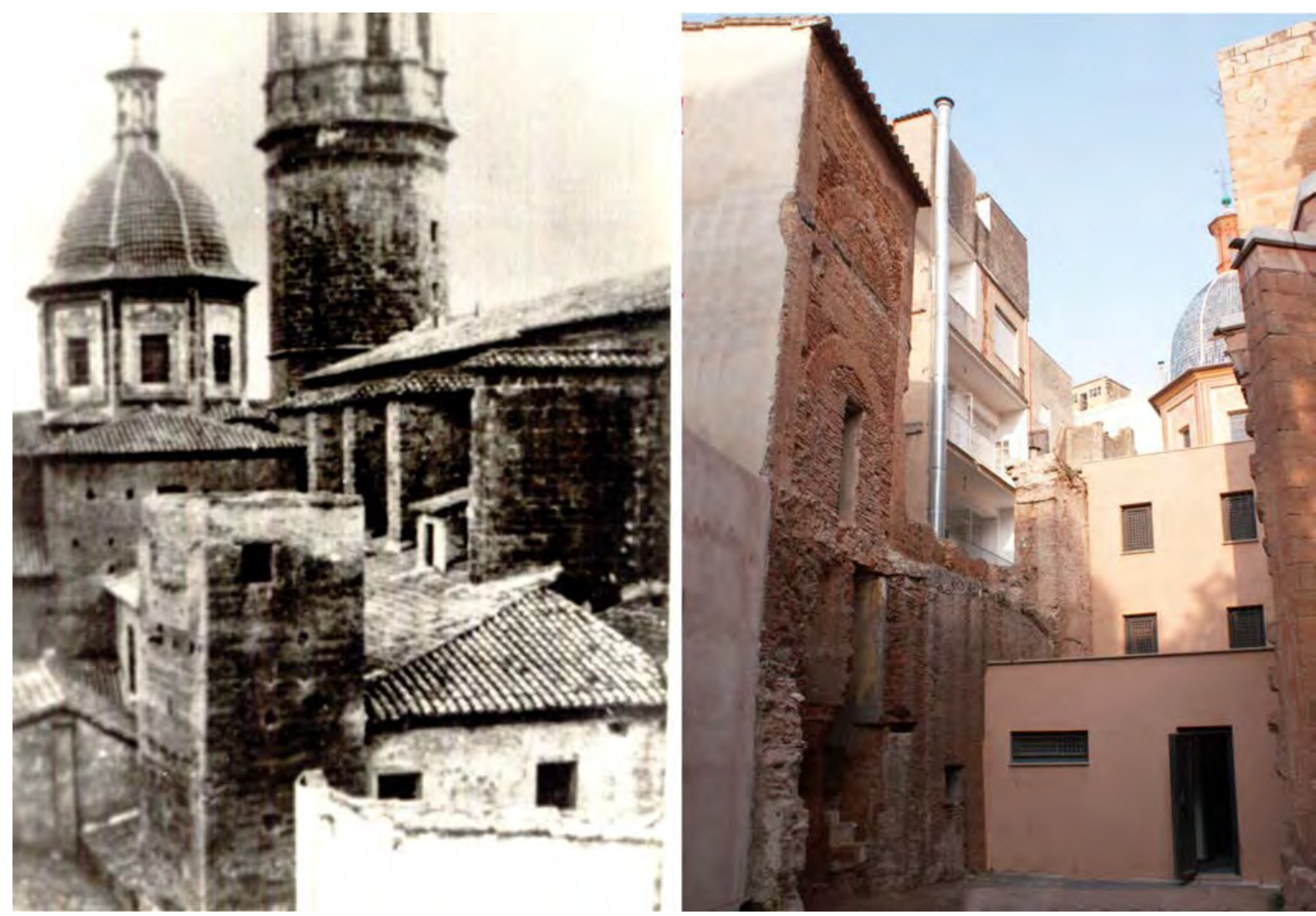

Figura 7. (1) Fotografía de la torre del Racó de I'Abadia a finales del siglo XIX (Fuente: Roca 1932). (2) Espacio entre la torre (izquierda) y la iglesia del Salvador (derecha). que se ha interpretado como callejón interior de la muralla. Fotografía: autores.

exhumar un tramo de la muralla occidental de la ciudad junto a la pared medianera del solar. En este sector el muro defensivo había sido derribado parcialmente en el siglo XIX y en su lugar se levantó un pequeño muro de mampostería que se apoyaba directamente sobre los cimientos medievales. La muralla alcanzaba $1,50 \mathrm{~m}$ de altura en la parte mejor conservada $\mathrm{y}$ tal y como se ha documentado en otros hallazgos del antiguo encintado, su técnica constructiva era la tapia de tierra calicostrada, con una cimentación de mampuesto de mortero de cal y cantos rodados que cubría un nivel de cantos rodados trabados con mortero de cal, de $30 / 40 \mathrm{~cm}$ de espesor, de mayor anchura que el lienzo defensivo. Lo novedoso es que bajo la base de cantos se documentó un nuevo cajón de tapia de mortero de $90 \mathrm{~cm}$ de altura. La altura de estas construcciones variaba de 0,90 a $1,5 \mathrm{~m}$ (Fig. 8, 1-2). Con todo, debido a la afección de otras construcciones contemporáneas no fue posible diferenciar la longitud de las tapiadas. Por otro lado, se conservaba parte de la disposición curvilínea que caracterizaba la planta de la muralla y el callejón de tierra batida interior que la acompañaba (Fig. 9).

\subsection{Racó de l'Abadia}

En el año 2008 el Servicio Municipal de Arqueología llevó a cabo una actuación arqueológica en el entorno del ábside de la iglesia del Salvador, que completó los resultados de las excavaciones de V. Verdegal y P. Ulloa, realizadas en los años 1989 y 1995 respectivamente. La intervención correspondía al área de una de las torres de la estructura defensiva. Para construir el espacio de la sacristía en el siglo XVIII la muralla 

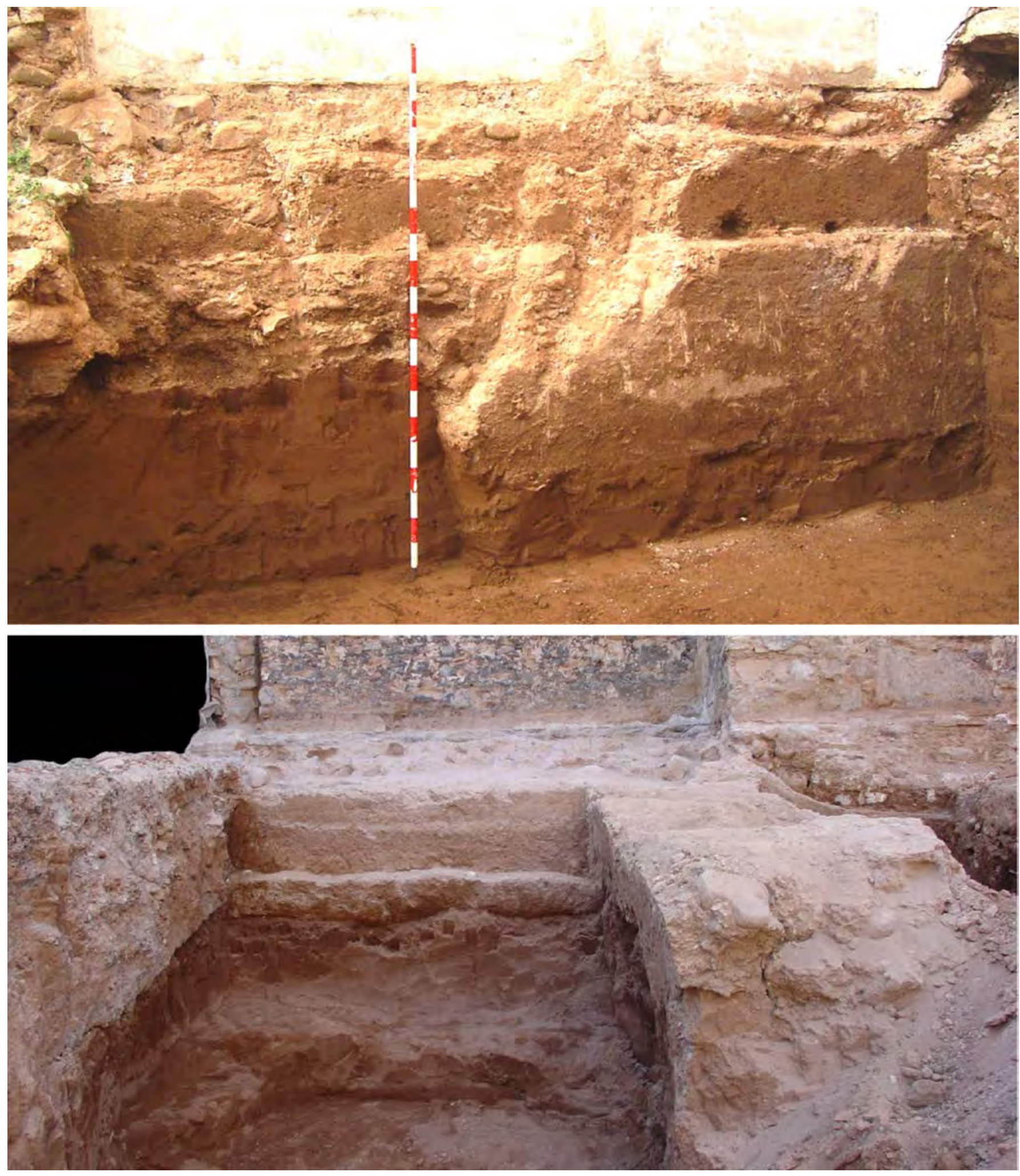

Figura 8. (1) Detalle de la cimentación de la muralla en la calle Mayor, 26. (2) Al fondo, cimientos de la muralla; en primer plano, base de encofrado y cimentaciones de edificios de época bajomedieval. Fotografía: autores. 


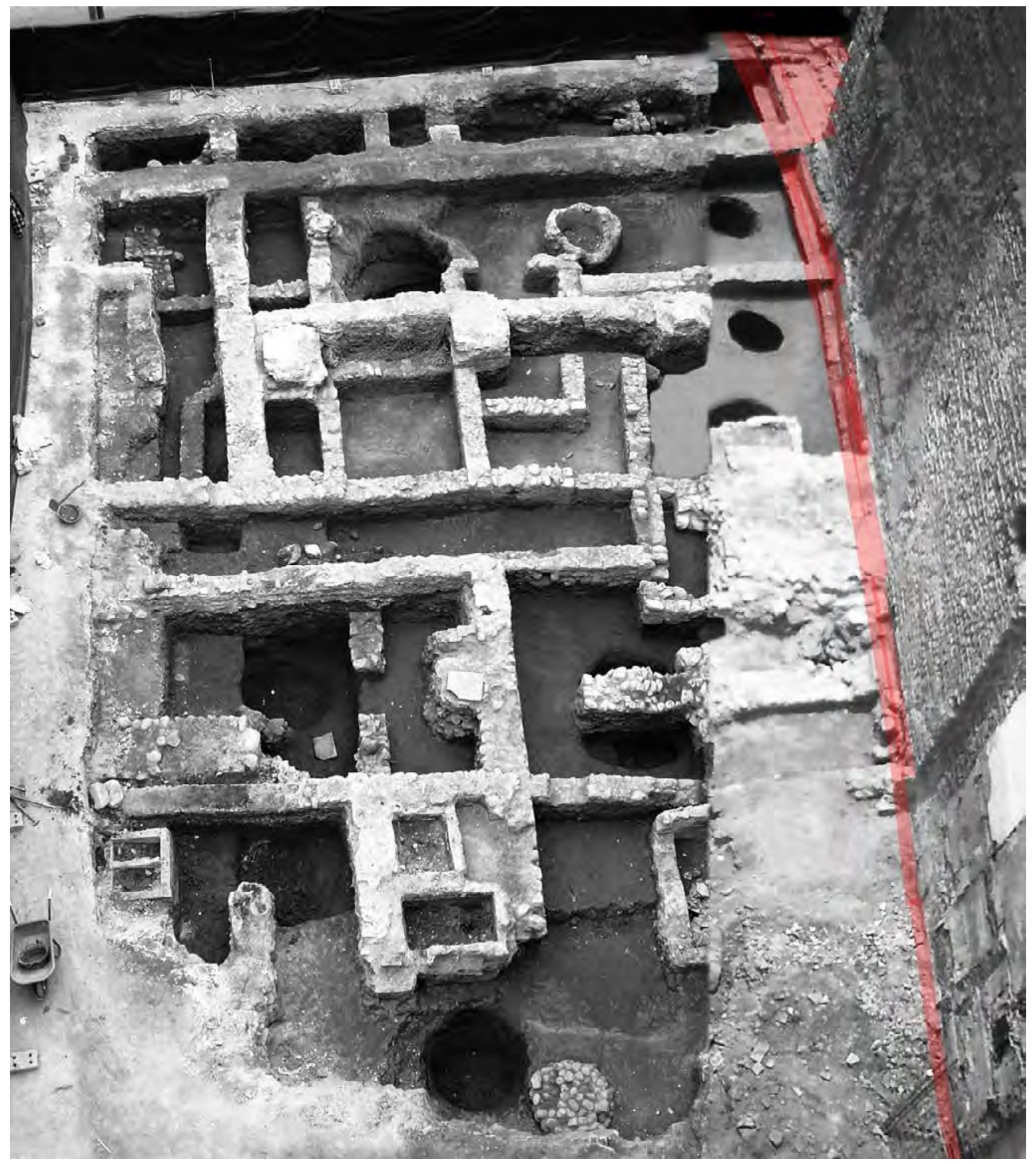

Figura 9. (Rojo) Trazado de la muralla conservada en la calle Mayor, 26. Fotografía: autores. 
había sido parcialmente derribada en este sector (Fig. $7,2)$. Durante estos trabajos se vació el tapial hasta llegar al calicostrado del paramento exterior (Fig. 10, 1). La planta baja de la torre formaba un único cuerpo con la tapia de la muralla, con la que coincide hasta el andén de mortero, aproximadamente a $6 \mathrm{~m}$ de altura. Por encima del mismo se documentó un espacio interior hueco, cerrado por una pared de ladrillos macizos, que conservaba dos arcos de ladrillo cegados dispuestos en dos franjas de $1,80 \mathrm{~m}$ la inferior y $3,50 \mathrm{~m}$ la superior (Fig. 11, a). El espacio hueco está delimitado por una capa de mortero de $80 \mathrm{~cm}$ de espesor, que conserva la impronta de la cubierta transitable de la torre. Este se apoyaba en un escalón formado por el estrechamiento de la capa perimetral de mortero, de $68 \mathrm{~cm}$. Debido a la yuxtaposición de las tapiadas, la altura del muro alrededor de este pavimento alcanza 1,10 m (Fig. 11, b).

La siguiente estructura que se documentó fueron los restos de una cimentación de cantos rodados trabados con mortero de cal que se apoyaba directamente en la cara interior de la muralla, sobre el callejón perimetral. Estos últimos restos se han fechado en época bajomedieval. Por otra parte, las excavaciones sacaron a la luz $2 \mathrm{~m}$ del lienzo defensivo de tapia de tierra calicostrada. Tenía $1 \mathrm{~m}$ de profundidad hasta alcanzar el paso de ronda, una base de cantos rodados y mortero de $40 \mathrm{~cm}$ de altura y $70 \mathrm{~cm}$ de la estructura de la cimentación, que también se elaboró con tapia de cantos rodados trabados con mortero (Melchor 2009, 2009-2010). La planta baja de la torre formaba un único cuerpo con la tapia de tierra de la muralla. Tras vaciarse el tapial, se pudieron documentar las tongadas de $9 \mathrm{~cm}$ de espesor (Fig. 10, 2), que pudieron conformar cajones de probablemente $90 \mathrm{~cm}$ de altura.

\subsection{Solar de la nueva Casa Abadía}

En el año 2009 el Servicio Municipal de Arqueología llevó a cabo una excavación preventiva en el solar colindante al ábside de la iglesia de El Salvador, pues se había proyectado la construcción de la nueva Casa Abadía. En este sector, la muralla había sido arrasada a mediados del siglo XIX. Con todo, se pudo registrar parte de la base de cimentación del lienzo murario que había sido elaborado con tapia de mortero. El tramo tenía $0,60 \mathrm{~m}$ de altura y $1,25 \mathrm{~m}$ en el sector dónde cubría una alcantarilla anterior a la construcción de la muralla. Se trataba de un agujero que daba salida a las aguas de lluvia. También se documentaron restos del alzado de tapia de tierra calicostrada, que no superaban $30 \mathrm{~cm}$ de altura conservada (Fig. 12, 1-2).

\subsection{Solar número 28 de la calle San Pascual}

Entre los años 2015 y 2019 el ayuntamiento de esta localidad proyectó una serie de intervenciones en este solar con el objeto de conservar y poner en valor los restos de un tramo de la muralla y una de las torres macizas. Durante los trabajos no salieron a la luz los restos del antemuro, pero se identificó parte del foso, que la urbanización de esta parte de la ciudad había colmatado. Se conservan $1,50 \mathrm{~m}$ de altura de la muralla a ambos lados de la torre que, tras el derribo, fue recrecida posteriormente con mampostería de ladrillos y piedra. En las paredes medianeras del solar se pudo observar que algunos tramos de la muralla y de la torre habían sido reutilizados en la construcción de las casas y de una carbonera que se le adosó a fines del siglo XIX. La torre tiene $4,10 \mathrm{~m}$ en su frente y 1,90 $\mathrm{m}$ en el lateral, siendo la altura conservada de 7,60 $\mathrm{m}$. Tiene una parte superior de tapia calicostrada y el tercio inferior de mampostería de piedra y mortero de cal (Fig. 13, 2). En cuanto a la ortofoto con tramas de colores que presentamos en este artículo (Fig. 14), esta no corresponde a un análisis sistemático de este sector de la fortificación desde el marco metodológico de la arqueología. El estudio de la secuencia estratigráfica y listado de los distintos componentes de la muralla se llevará a cabo en futuros trabajos.

\subsection{Obras de la calle Zaragoza}

En el año 2019 se iniciaron distintas actuaciones arqueológicas en la calle Zaragoza que permitieron documentar la base de mampostería de otra torre que se hallaba bajo el firme de la calle y de las casas. Esta se encontraba arrasada hasta la cimentación (Fig. 15). Los trabajos todavía no se han publicado, pero quizá haya que relacionar este descubrimiento con la puerta de la muralla que consideramos debió estar localizada junto al antiguo Camí de la Mar. 

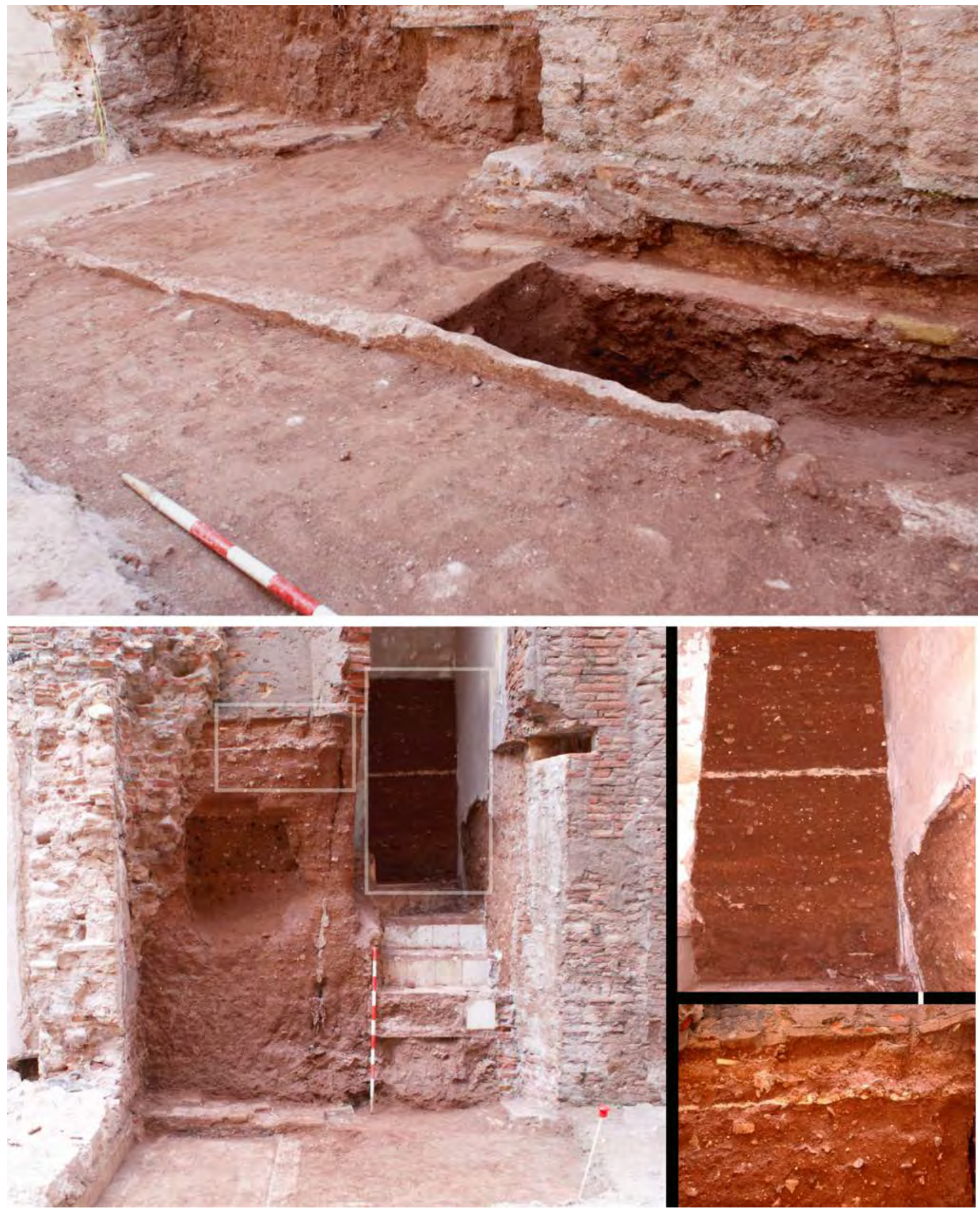

Figura 10. (1) Detalle de la calicostra de la fachada interior de la muralla. Se halló frente a la torre y bajo el pavimento de la sacristía del Racó de I'Abadia. (2) Tongadas de tierra de tapia acerada y capas de mortero registradas en el interior de la torre. Fotografía: autores. 


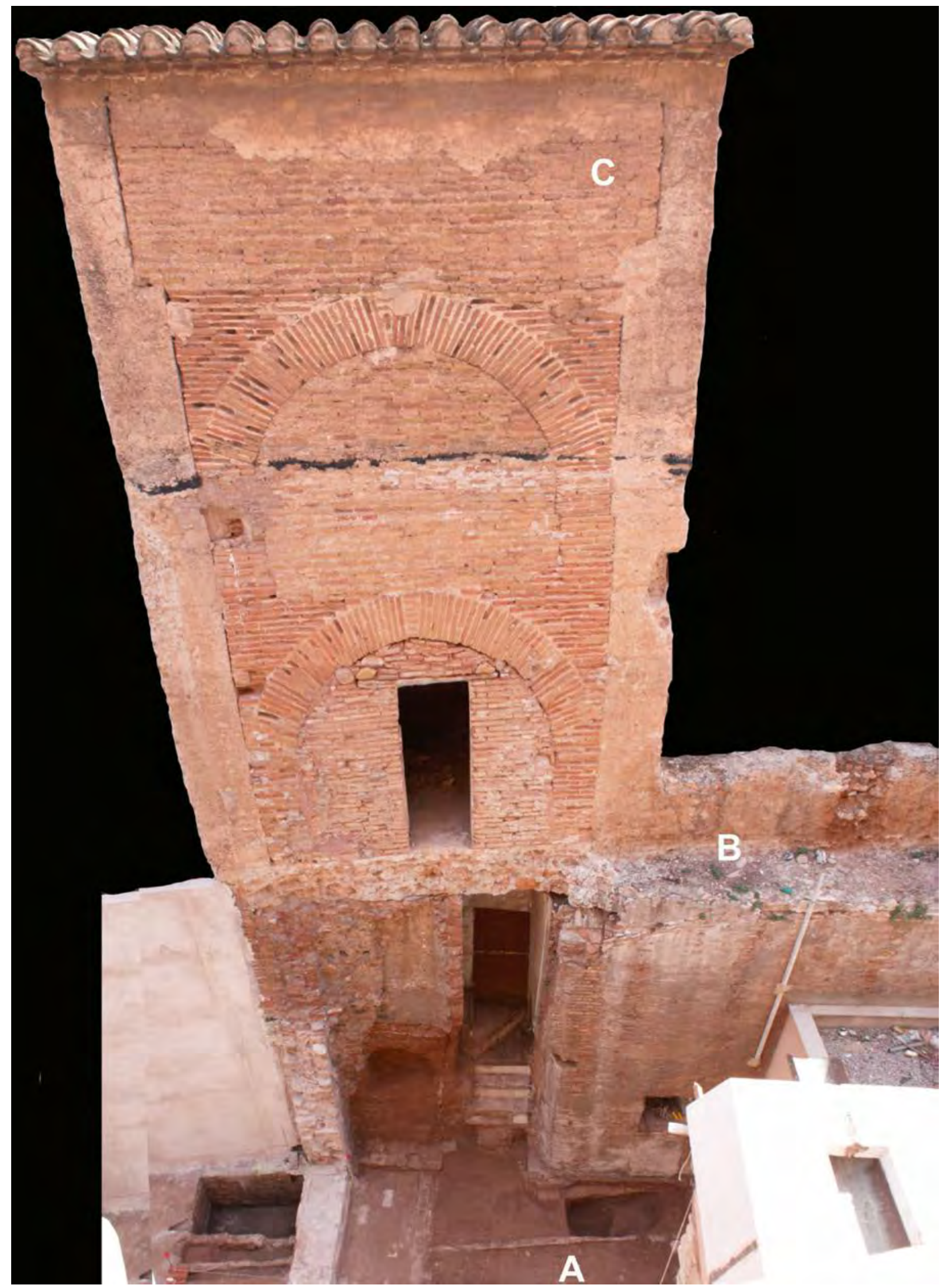

Figura 11. (A) Restos del tapial de la muralla localizados en la base de la torre del Racó de l'Abadia; (B) Parapeto del paso de ronda que se conserva sobre el muro de la antigua sacristía; (C) Cuerpo superior de la torre. Fotografía: autores. 


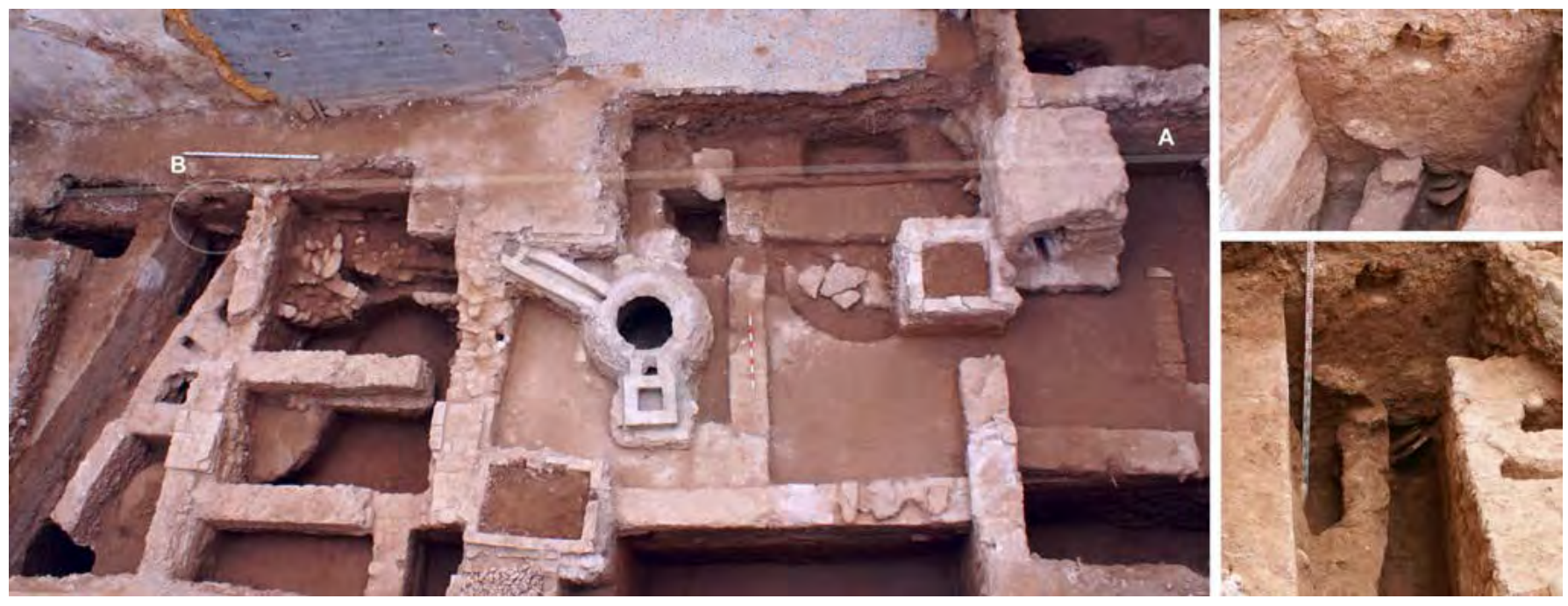

Figura 12. (1) Alineación de la muralla (A) y localización del canal de desagüe (B). (2) Detalle del desagüe y de la cimentación de la muralla. A ambos lados, construcciones que se adosan al lienzo defensivo. Fotografía: autores.
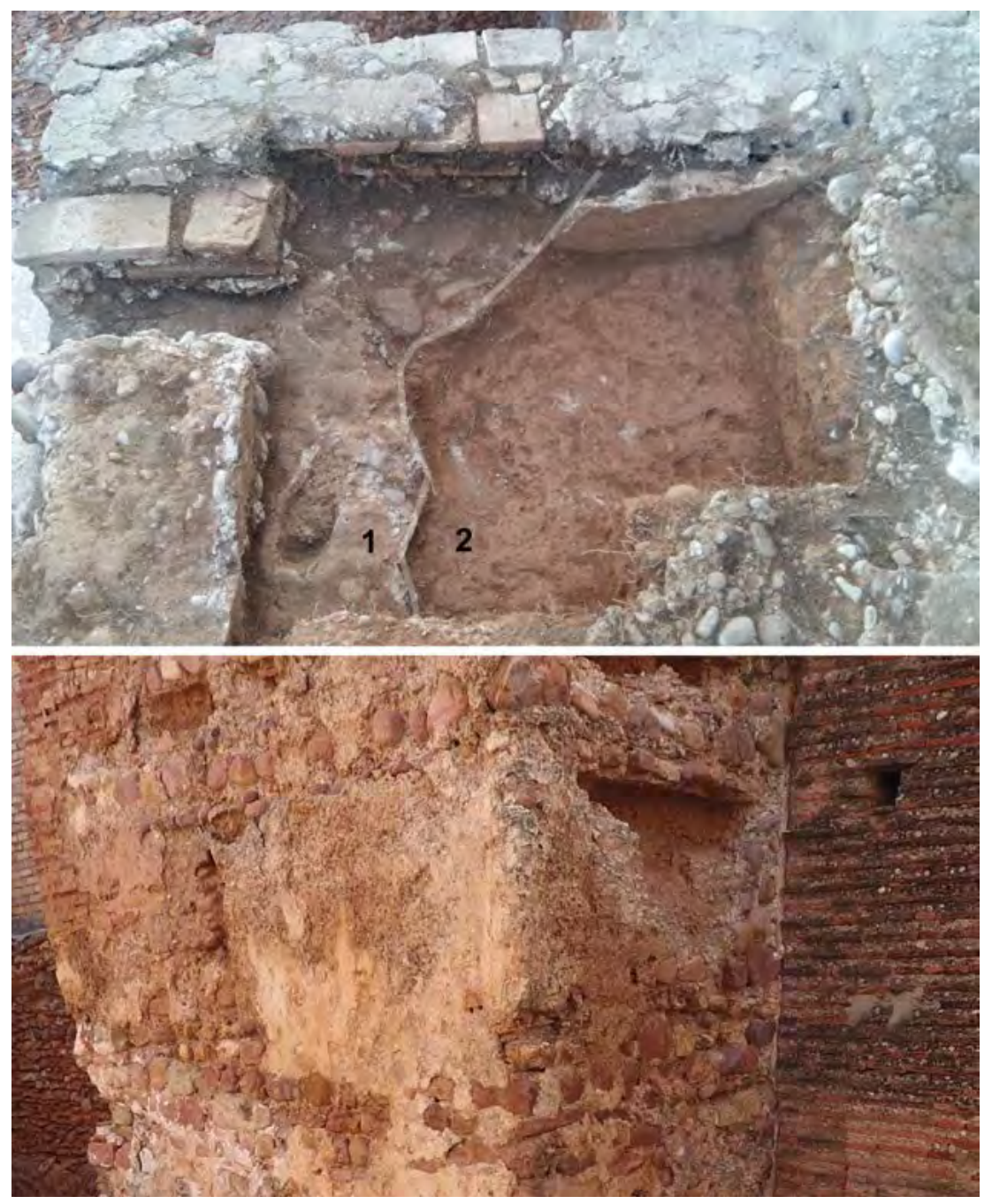

Figura 13. (1) Parte superior de la torre de la calle San Pascual, 26-28. Las obras de mampostería se llevaron a cabo en el siglo XIX (1, 1). El relleno original se conserva en la mitad oriental $(1,2)$. (2) Detalle del paramento exterior de la torre donde se observan las verdugadas de mampuesto. Fotografía: autores. 


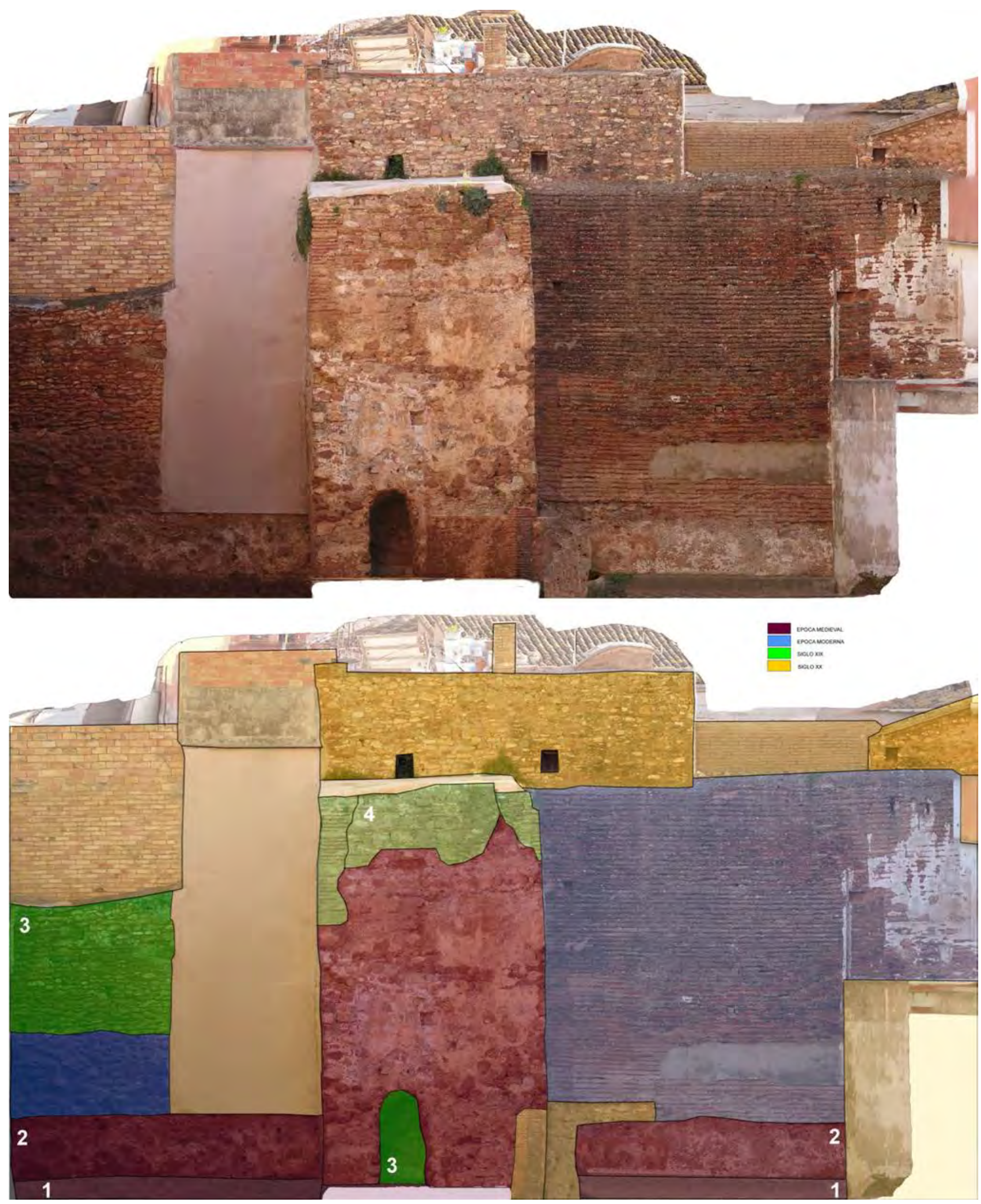

Figura 14. Ortofoto de la muralla de la calle San Pascual. (1) Cimentación de la muralla. (2) Paramento exterior de la muralla. (3) Restos de la carbonera de fines del siglo XIX y apertura practicada en la base de la torre. (4) Reconstrucción de la torre de principios del siglo XIX. Fotografía: Museo Arqueológico de Burriana. 


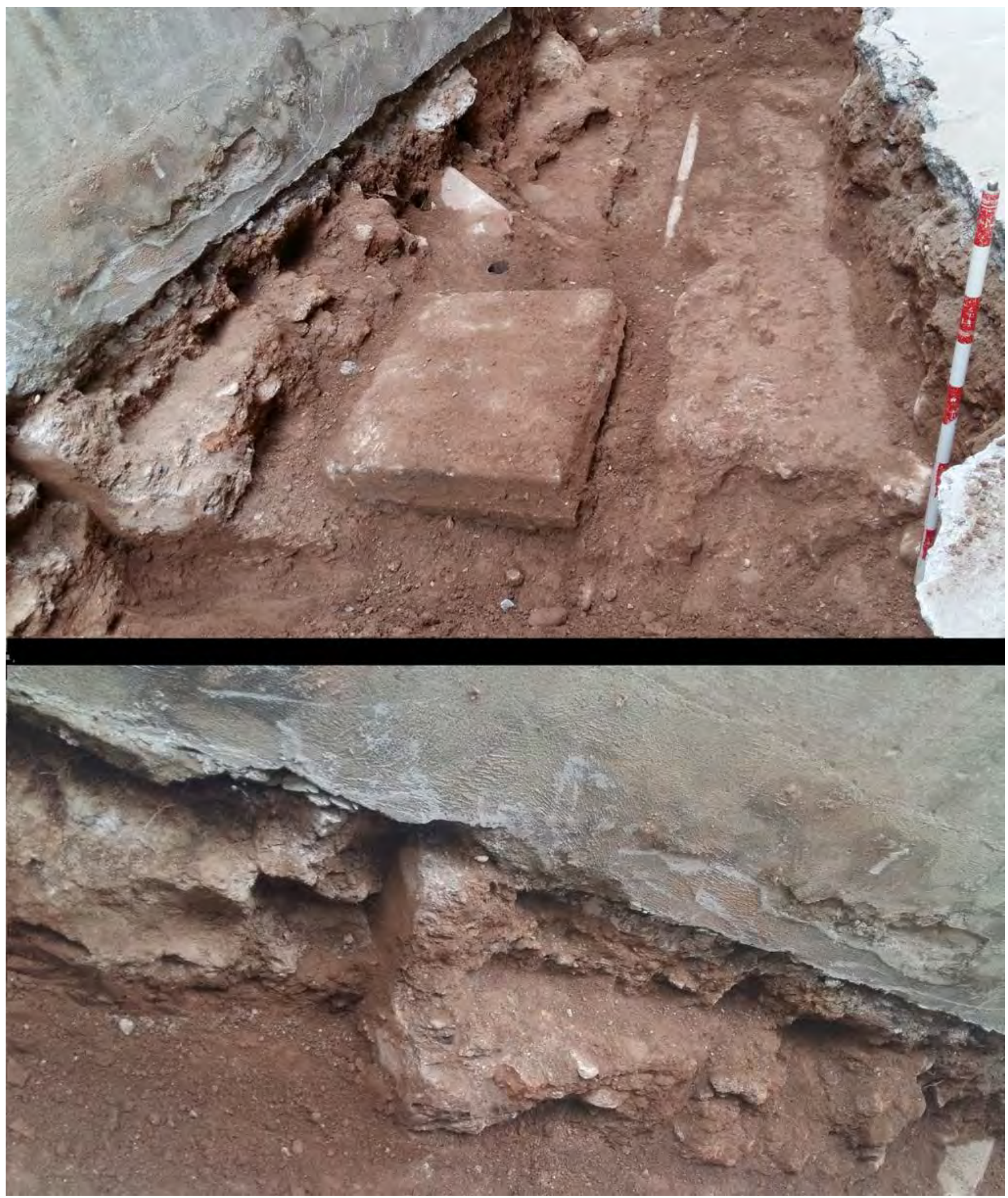

Figura 15. (1) Cimentación de la torre de la calle Zaragoza. (2) Detalle del paramento del encofrado de la cimentación de la torre bajo las casas. Fotografía: autores. 


\subsection{Obras de la calle Mayor}

En el año 2013 el Servicio Municipal de Arqueología realizó el seguimiento arqueológico de otra zanja en la calle Mayor, esta vez frente al solar número 26 y paralela a la zanja abierta en el año 1967, que permitió documentar una nueva sección de la estructura defensiva, que correspondía a cimentaciones de mortero de cal y cantos rodados. Las estructuras defensivas que salieron a la luz correspondían al paso de ronda interior de $4 \mathrm{~m}$ de amplitud, la cimentación de la muralla de $1,80 \mathrm{~m}$ de espesor (Fig. 16, 2), el espacio de $6 \mathrm{~m}$ entre estas estructuras y la acitara, el propio antemuro de 1,30 $\mathrm{m}$ de espesor, una cimentación de $90 \mathrm{~cm}$ (Fig. 16, 1) y $3 \mathrm{~m}$ de espacio hasta alcanzar el foso, desde el cual arrancaba un puente de mampostería de época moderna, cuando se procedió a anular el antiguo Portal de Valencia, y a abrir una puerta en la muralla, esta vez alineada con la nueva calle Mayor (Melchor 2013).

\subsection{Solar número 6 de EI Pla}

Por último, la excavación realizada por las arqueólogas Sandrine Delaporte y Mónica Claramonte en el solar

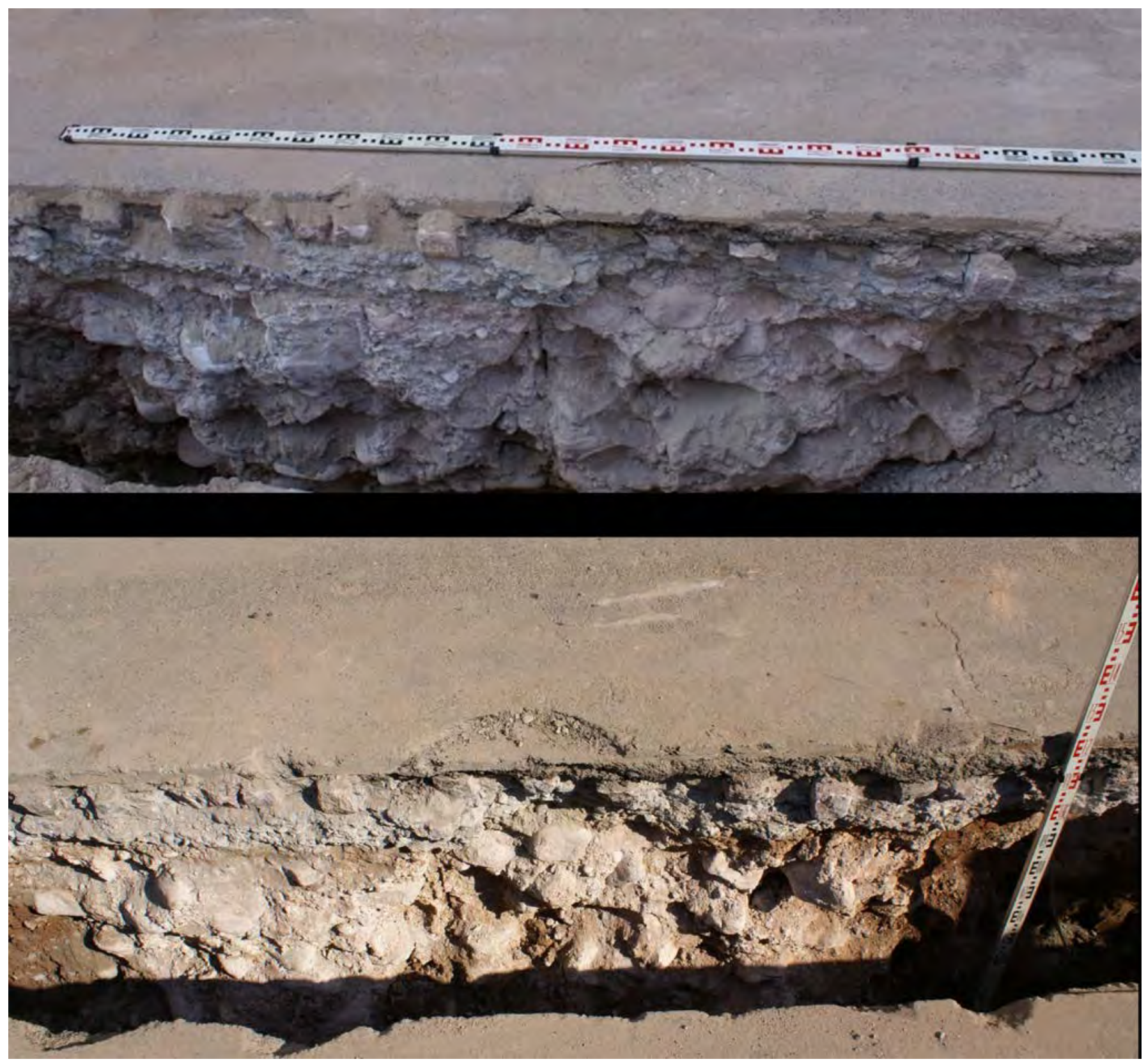

Figura 16. (1) Cimentación del antemuro. (2) Cimentación de la muralla. Fotografía: autores. 
número 6 de El Pla en el año 2016, todavía inédita, ha permitido documentar vestigios del foso. Este se hallaba protegido por un sólido muro de mampostería de piedra y mortero de cal con enlucido de color blanco. Sin embargo, no podremos precisar la cronología de esta estructura hasta que se realicen nuevas excavaciones, ya que los materiales registrados hasta la fecha no permiten aclarar la fecha de su construcción.

\section{FUNDAMENTOS CONSTRUCTIVOS}

A la hora de abordar el estudio de la arquitectura militar de la ciudad de Burriana podemos considerar, por un lado, el análisis de la apariencia formal en función de los restos que se han excavado; y por otro, el relativo al procedimiento empleado para llevar a cabo la fortificación. Los elementos que han sido objeto de estudio son las estructuras arquitectónicas que se erigieron en diferentes puntos del recinto, y entre otras cuestiones incluye los acabados de las construcciones de tapial, es decir, el tratamiento aplicado a los cajones para evitar el efecto de los agentes erosivos. Por otro lado, la muralla se reforzó con otros elementos constructivos, nos referimos a la adición de torres de planta cuadrangular distribuidas a lo largo del perímetro murado. Aparte de torres, la muralla contaba con adarves o pasos de ronda elevados. En la tabla 1 adjunta exponemos las características morfológicas y constructivas de los diferentes sectores de la ciudad. Respecto a los fosos que envolvían la fortificación, existen pocas referencias materiales. Por otro lado, el tema ha sido poco tratado en la bibliografía, hay menciones solo en algunas intervenciones como los datos revelados en el solar de la calle San Pascual y en la calle Mayor, pero poco más podemos deducir de ello.

En un somero estudio de las dimensiones que se referencian en las tablas 2 y 3 , destaca el grado de estandarización que alcanzó el sistema constructivo, sobre todo en la técnica del tapial o fábrica encofrada en la construcción del recinto urbano fortificado. En algunos casos se hace referencia a reparaciones de mampostería sobre la fachada de la muralla. Respecto a las fábricas de ladrillo, están relativamente poco extendidas en la reparación de la muralla, apareciendo en algunos lienzos de la torre documentada en el Racó de l'Abadia. No ha aparecido en la parte baja ni en las cimentaciones, sino en la parte alta de la torre.
En este sector se configura como una decoración de arcos ciegos que, como se ha mencionado, no es una construcción coetánea a la muralla de tapial sino una reconstrucción.

La mayoría de las defensas son de tapia de tierra calicostrada con alta dosificación en cal y ofrecen unas pautas de dimensión de los cajones con una anchura que oscila, según los tramos, entre 1,80 y $2,00 \mathrm{~m}$. La argamasa de cal y arena tenía un ancho de 6 a $8 \mathrm{~cm}$ y se extendía al mismo tiempo tanto en la base como en las paredes del cajón, antes de recibir la nueva tongada de tierra. Una vez pisada esta, el proceso de construcción continuaba con una nueva tongada hasta alcanzar la altura del cajón. La anchura de la calicostra oscilaba entre 10 y $14 \mathrm{~cm}$. Entre la arcilla del tapial se observa gran cantidad de pequeños fragmentos cerámicos $\mathrm{y}$ óseos. Esta obra encofrada, como medida de protección, se erige sobre un zócalo o basamento de mampuesto de cantos de río y mortero de cal. Los distintos hallazgos muestran como la anchura de la cimentación varía de 2 a 2,40 m, mientras que su profundidad es de 40 o $60 \mathrm{~cm}$, a excepción del tramo que cubre el agujero que daba salida a las aguas de lluvia que pasa por debajo de la muralla en la antigua Casa Abadía y del cajón de tapia de mampuesto de mortero y piedra sobre el que aparece dispuesto el alzado de tapia de tierra en la calle Mayor, 26. Sin embargo, como se ha indicado, la muralla ha sido muy alterada y apenas se conservan cajones. Las líneas de separación entre los mismos no se perciben y tampoco hay agujales, dejados por las agujas de madera para apoyar los tableros. Las separaciones entre los cajones quizá fueron ocultadas por reiteradas intervenciones que las han desfigurado. Por tanto, no tenemos elementos que ayuden a la lectura de la modulación del encofrado y por tanto a la identificación de cada una de las tapias.

Respecto al remate original, este debería ser almenado, el cual coronaría la obra encofrada. Sin ser posible extrapolarlo a toda la fortificación, pues los lienzos presentarían varias alturas, el hallazgo mejor conservado se ha documentado en la torre del Racó de l'Abadia. La torre conserva el andén de paso de mortero de cal. Este tiene $32 \mathrm{~cm}$ de espesor. A los 4,30 m de altura de la torre habría que sumar $1,40 \mathrm{~m}$ de profundidad hasta la cimentación (Ulloa 2000) y aproximadamente $1 \mathrm{~m}$ que deberían tener las almenas. Por tanto, podríamos plantear que el alzado teórico de la muralla podía ser de aproximadamente $7 \mathrm{~m}$. 


\begin{tabular}{|c|c|c|c|c|c|c|}
\hline $\begin{array}{c}\text { ESTRUCTURA } \\
\text { ARQUITECTÓNICA }\end{array}$ & $\begin{array}{c}\text { RESTOS } \\
\text { CONSERVADOS }\end{array}$ & ESPESOR & $\begin{array}{l}\text { CAJÓN } \\
\text { altura }\end{array}$ & $\begin{array}{c}\text { SISTEMA } \\
\text { UTILIZADO }\end{array}$ & $\begin{array}{c}\text { DIMENSION } \\
\text { CONSERVADA } \\
\text { (longitud } \times \\
\text { anchura } \times \\
\text { altura) }\end{array}$ & SECTOR \\
\hline \multirow{11}{*}{ MURALLA } & Lienzo & & & Tapia real & $280 \times i ? \times 89$ & C/ Sant Joan \\
\hline & Lienzo & & & $\begin{array}{l}\text { Mortero } \\
\text { encofrado }\end{array}$ & $1500 \times i ? \times 100$ & C/ San Pascual \\
\hline & Lienzo & 190 & & Tapia real & $1800 \times 190 \times 30$ & $\begin{array}{c}\text { Nueva Casa } \\
\text { Abadía }\end{array}$ \\
\hline & Lienzo & 200 & & $\begin{array}{c}\text { Tapia real } \\
\text { calicostrada }\end{array}$ & $1600 \times 200 \times 800$ & Racó de l'Abadia \\
\hline & Lienzo & & & $\begin{array}{l}\text { Restos de } \\
\text { encofrado }\end{array}$ & 60 (altura cons.) & $\begin{array}{c}\text { Antigua Casa } \\
\text { Abadía }\end{array}$ \\
\hline & Cimentación & 220 & & Mampostería & $300 \times 220 \times 90$ & C/ Mayor \\
\hline & Cimentación & 180 & 90 & Mampostería & $\begin{array}{c}2900 \times 180 \times \\
70 / 150\end{array}$ & $\begin{array}{l}\text { C/ Mayor-Forn } \\
\text { la Vila }\end{array}$ \\
\hline & Cimentación & & & Mampostería & $280 \times i ? \times 60$ & C/ Sant Joan \\
\hline & Cimentación & & & Mampostería & $1600 \times 200 \times 400$ & Racó de l'Abadia \\
\hline & Cimentación & 190 & & Mampostería & $1800 \times 190 \times 700$ & $\begin{array}{l}\text { Nueva Casa } \\
\text { Abadía }\end{array}$ \\
\hline & Cimentación & & & Mampostería & $1500 \times i ? \times 50$ & C/ San Pascual \\
\hline \multirow{6}{*}{ TORRE } & Lienzo & $130 / 140$ & & Mampostería & $\begin{array}{c}\text { luz } 330 \times 170 \\
\text { entrada } 185 \\
\text { (anchura) }\end{array}$ & Plaza Mayor \\
\hline & Lienzo & $80 / 68$ & & & & \\
\hline & 90 (aprox) & $\begin{array}{c}\text { Mortero } \\
\text { encofrado y } \\
\text { ladrillo }\end{array}$ & $\begin{array}{l}400 \times 500 \\
\times 1400\end{array}$ & Racó de l'Abadia & & \\
\hline & Lienzo & maciza & 90 (aprox) & $\begin{array}{l}\text { Mampostería/ } \\
\text { tapia mixta }\end{array}$ & $410 \times 190 \times 760$ & C/ San Pascual \\
\hline & Cimentación & maciza & & Mampostería & $405 \times 90 \times 40$ & $\mathrm{C} /$ Zaragoza \\
\hline & Cimentación & macizo & & Mampostería & $440 \times 80 \times 90$ & C/ Mayor \\
\hline ANTEMURO & Cimentación & $120 / 130$ & & Mampostería & $300 \times 120 \times 90$ & C/ Mayor \\
\hline \multirow{2}{*}{ FOSO } & Muro & 70 & & $\begin{array}{l}\text { Mampostería } \\
\text { enlucida }\end{array}$ & $70 \times 75 \times 90$ & C/ Mayor \\
\hline & Muro & 78 & & $\begin{array}{l}\text { Mampostería } \\
\text { enlucida }\end{array}$ & & El Pla \\
\hline BERMA & Pavimento & 320 & & Tierra batida & $300 \times 320$ & C/ Mayor \\
\hline PASO DE RONDA & Pavimento & 400 & & Tierra batida & $300 \times 400$ & $\mathrm{C} /$ Mayor \\
\hline
\end{tabular}

Tabla 1: Listado de estructuras arquitectónicas y dimensiones (en cm). 


\begin{tabular}{|l|l|l|l|l|l|}
\hline \multicolumn{1}{|c|}{ SECTOR } & TAPIA & MAMPUESTO & LADRILLO & $\begin{array}{c}\text { ZÓCALO DE } \\
\text { MAMPUESTO }\end{array}$ & $\begin{array}{c}\text { ZÓCALO DE } \\
\text { TAPIA }\end{array}$ \\
\hline Calle Mayor & & & & & \\
\hline C/ Sant Joan & & & & & \\
\hline Antigua Casa Abadía & & & & & \\
\hline $\begin{array}{l}\text { C/ Mayor esquina } \\
\text { Forn de la Vila }\end{array}$ & & & & & \\
\hline Racó l'Abadia & & & & & \\
\hline Nueva Casa Abadía & & & & & \\
\hline C/ San Pascual & & & & \\
\hline
\end{tabular}

Tabla 2: Listado de sistemas constructivos en los muros.

\begin{tabular}{|l|l|l|l|l|l|}
\hline \multicolumn{1}{|c|}{ SECTOR } & TAPIA & MAMPUESTO & LADRILLO & $\begin{array}{c}\text { ZÓCALO DE } \\
\text { MAMPUESTO }\end{array}$ & $\begin{array}{c}\text { ZÓCALO DE } \\
\text { TAPIA }\end{array}$ \\
\hline Calle Mayor & & & & & \\
\hline Plaza Mayor & & & & & \\
\hline Racó de l'Abadia & & & & & \\
\hline Calle San Pascual & & & & & \\
\hline Calle Zaragoza & & & & \\
\hline
\end{tabular}

Tabla 3: Listado de sistemas constructivos en las torres.

Del antemuro solo se ha registrado parte de su cimentación elaborada con mampuesto de cantos de río y mortero de cal. En función de los hallazgos, se puede estimar una anchura de aproximadamente 1,30 m, es decir, inferior a las medidas de la muralla. Por otro lado, sabemos dónde se abrían los portales, pero apenas se conservan algunos restos como los del Portal de Valencia. Las referencias gráficas que se han encontrado son representaciones reconocidas en el dibujo de Viciana (1564) y en una pintura mural costumbrista publicada por N. Mesado (1991: 192) (Fig. 17). Se trataría posiblemente de portales con dos torres, que se hallarían retranqueados respecto a la muralla, como lo prueba el diseño urbanístico que dejaron en el parcelario actual los portales de Valencia y Tortosa. El retranqueo de estos portales evidencia que su construcción debió influir en la disposición del lienzo murario y que fue necesario tener previsto su emplazamiento cuando se trazó el mismo. También debieron existir otras puertas de acceso, como la que estaría ubicada junto a la calle Zaragoza, en el antiguo Camí de la Mar. Desde el punto de vista constructivo no se puede aportar más información, pues no sabemos nada más del resto de portales.

En cuanto a las torres, la arqueología ha sido capaz de reconocer torres cuadradas macizas en su primer cuerpo en el solar de la calle San Pascual, calle Zaragoza y calle Mayor. Se trataría de estructuras macizas de mampuesto de mortero de cal y cantos de río en el primer cuerpo y de tapia de fábrica mixta de tierra y piedras, en la parte superior. El lienzo del muro estaría trabado a estas torres. Sin embargo, en el resto de paramentos documentados, las obras de derribo o las distintas reparaciones han ocultado las relaciones estratigráficas entre los lienzos y las torres, por lo que no hemos podido averiguar qué estructura se traba a cuál.

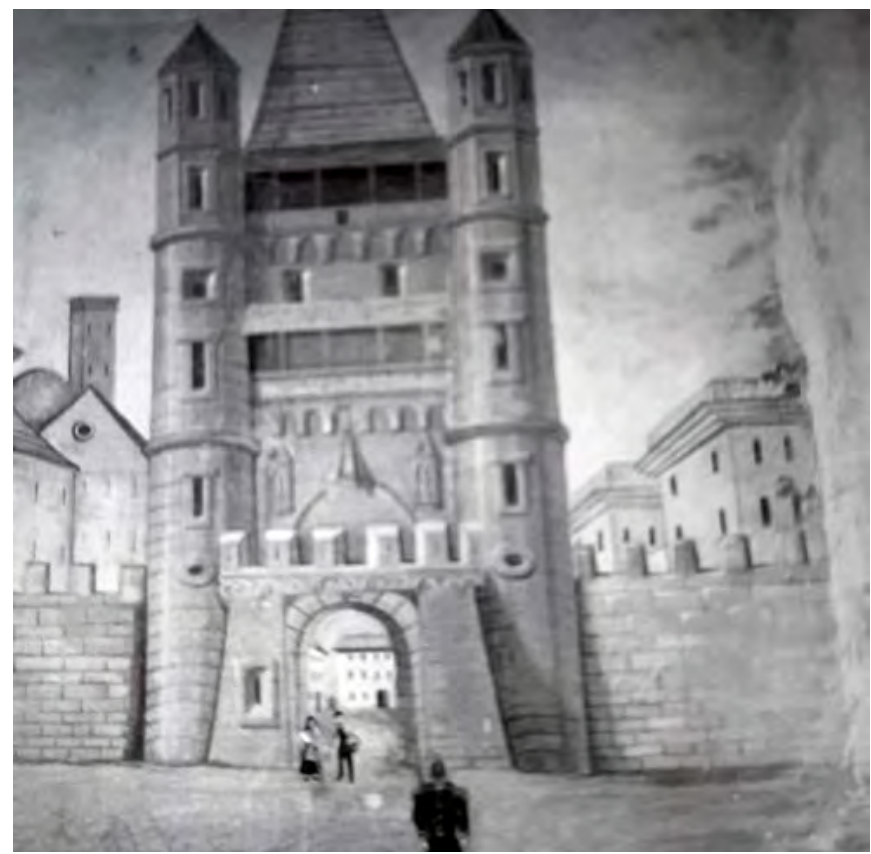

Figura 17. Pintura mural de mediado el siglo XIX localizada en las habitaciones señoriales de una alquería de Burriana. Se trata probablemente de una representación ideal del Portal de Valencia. Fuente: Mesado (1991: 192). 
Las dimensiones de la base de las torres son aproximadamente $2 \times 4 \times 2 \mathrm{~m}$. La que se conserva en el interior de la Casa Abadía tiene base maciza de tapia real. Fue construida de forma simultánea a la muralla. El relleno de la torre y del lienzo, consideramos que se efectuó simultáneamente, es decir, son continuos. El perímetro exterior es de $4 \times 5 \times 4 \mathrm{~m}$ y si hipotéticamente añadimos una hilada de almenas, la altura teórica sería de aproximadamente 13 o $14 \mathrm{~m}$.

\section{APROXIMACIÓN CRONOLÓGICA $Y$ CONSIDERACIONES FINALES}

La fecha de construcción de estas defensas la tenemos que basar en paralelos tipológicos y características arquitectónicas ante la falta casi total de información histórica documental. La realización de excavaciones arqueológicas a lo largo de los últimos años tampoco ha permitido establecer cronologías claras. En cuanto a la documentación de técnicas constructivas de encofrado de tapial en recintos urbanos andalusíes, resultan de gran ayuda los trabajos de P. Gurriarán (Gurriarán y Sáez 2002, entre otros). Estas obras se caracterizan por una marcada homogeneidad, con preferencia por la tapia de tierra calicostrada con cimiento de mampostería.

Además del estudio de publicaciones relacionadas con recintos fortificados próximos geográficamente a la localidad de Burriana en los que se han constatado fábricas de época islámica, se ha considerado necesario ampliar el análisis a la arquitectura hispanomusulmana de otros territorios más alejados como Alicante, Murcia y Andalucía, pese a que no se trata de unidades administrativas similares. Los paralelos constructivos nos permitirán disponer de testimonios más fidedignos para intentar realizar una aproximación cronológica lo más rigurosa posible. En España las fortificaciones islámicas son muy difíciles de datar debido a la falta de fechas seguras, por lo que podemos considerar las cronologías atribuidas a otras fortificaciones que comparten ciertas características con el caso que estudiamos, lo que nos ayudará a efectuar una hipótesis cronológica. En lo relativo al análisis de fortificaciones islámicas en territorio valenciano hay estudios muy interesantes. Estas investigaciones están relacionadas con trabajos de excavación, consolidación y puesta en valor de ciertos husün, como por ejemplo la alcazaba de Onda (Navarro y Estall 2011), el Castell de Xivert en Alcalà de Xivert (Bazzana 1976; Bazzana et al. 1988; Hofbauerová y De
Antonio 2001), el Castell Vell en Castellón de la Plana (García y Palmer 2018), la ciudad y alcazaba de Denia (Azuar 1989) y el Cerro Sopeña en Segorbe (Palomar y Berga 2005), entre otras intervenciones patrimoniales. En las tierras valencianas la tapia ha sido muy utilizada durante el periodo andalusí, pero para entender mejor los sistemas constructivos utilizados habrá que esperar a tener un estudio sistemático de los diversos distritos. En el castillo de Onda todos los lienzos de muralla y torres localizados junto al palacio de la alcazaba tienen zócalo de mampostería dispuestos en hiladas sobre el que se levanta la obra de tapial de tierra. Esta fábrica, reparada mediante forros de mampostería, se ha fechado en el siglo XI (Navarro y Estall 2011: 77-78). Por su parte, en el Castell Vell de Castellón el tapial se ha fechado en época almohade, momento en que el castillo se organiza en un espacio amurallado dividido en tres recintos (García y Palmer 2018: 86-87). El hisn de Xivert, pese a que no se sabe con exactitud, se ha datado a finales del siglo X y principios del XI (Arquer y Falomir 2008), conservándose un profundo foso, los restos de un antemuro y el tapial calicostrado en la construcción de la torre de Poniente y la muralla que cierra el albacar donde queda englobado el lienzo de la muralla de Alafia. En este muro se han documentado diversas superposiciones de volúmenes. La primera franja del lienzo es de mampostería ordinaria, es decir de piedras sin trabajar y ripios, a continuación un zócalo de mampostería encajonada, mientras que la tercera parte del paño es de tapial calicostrado y decorado con sillería fingida de aparejo isodomo (Hofbauerová y De Antonio 2001). Respecto al castillo de Denia, la alcazaba estaba separada del resto de la fortificación por una muralla de diversas facturas. Los muros de la fortificación islámica se encontraban muy alterados por construcciones posteriores, sin embargo, vestigios del lienzo de tapial se han documentado por todo el amurallamiento, siendo el hallazgo más importante la base de tres torres macizas de tapial localizadas en el flanco de levante. La cronología de estos restos se ha fijado en el segundo cuarto del siglo XII (Azuar 1989: 31, 34).

Por otro lado, si comparamos las estructuras arquitectónicas procedentes de husūun en relación a mudūn o qurà, la falta de referencias de los conocimientos empleados para llevar a cabo las fortificaciones que estas encierran hace que resulte algo imprecisa la información. Se puede adelantar que en la kura de Balansiya el número de ciudades es reducido, y el estudio de las fortificaciones también lo es. Al-Rāzī en el siglo X describe 
la madīna Buryāna (Burriana), Murbāțir (Sagunto), Balansiya o al-Turab (Valencia), al-ğazīra (Alzira), Satibat (Xàtiva) y Yundāra (Ondara). En el siglo XI los testimonios se han ampliado a Unda (Onda), Qalayayra (Cullera), Dannya (Denia), Qustantaniya (Cocentaina) y la madīna Šubrub (Segorbe), entre algunas otras (Vallvé 1986: 292; Soler 2002: 52). Hay, por lo tanto, pocos datos concretos. Las excavaciones han sacado a la luz murallas en la propia capital y en las mudūn de Alzira y Burriana que, como se ha mencionado, eran centros de un 'amal.

De todas las ciudades la cerca muraria de Balansiya es por ahora la más estudiada. Sabemos que no fue una obra unitaria, sino el resultado de diferentes intervenciones constructivas que se acometieron entre los siglos XI y XII, cuando el recinto se amplió hacia el este y el sur, hasta ocupar la isla fluvial que delimitaba el río Turia y uno de los brazos fluviales. Con todo, algunos de los tramos estudiados presentan diferencias, por ejemplo, la zona noroeste se ha fechado en el siglo XI. En esta época al lienzo se adosaron torres de planta circular cada 30-33 m, mientras que el resto presenta torres de base cuadrada. En ambos tramos se añadió el antemuro a la muralla (Arraiz y Andújar 2010). Respecto a las torres de cuerpo rectangular o trapezoidal y frente semicircular, estas tienen una anchura de $5 \mathrm{~m}$ y una altura de $14 \mathrm{~m}$. Fueron construidas con mampostería en su cara exterior y con relleno compacto de mortero. En la zona de levante, en cambio, se han registrado torres de planta cuadrada de $4 \mathrm{~m}$ de lado con el zócalo construido con mortero y el cuerpo de tapial de tierra. La separación entre una y otra torre es de $22,5 \mathrm{~m}$ hasta el adarve, tal y como se observa en la torre conservada en la calle Caballeros, 36 (Pascual y Martí 2002: 298). Respecto al lienzo de muralla del siglo XI, este era de tapial de mortero, las cajas medían $90 \mathrm{~cm}$ de altura y se disponían sobre cimientos cuya profundidad variaba de poco más de $1 \mathrm{~m}$ a casi $5 \mathrm{~m}$, debido a la distinta consistencia del terreno. El trazado es rectilíneo durante centenares de metros. En la segunda mitad del siglo XII se derruyó la mayor parte de la grada oriental del circo, respetando tan solo el muro exterior, al que se le adosó una muralla de nueva fábrica, construida esta vez con tapial de mortero que variaba de 1,9 a $2 \mathrm{~m}$ de espesor. La técnica constructiva empleada fue mampostería encajonada con traba de argamasa y acabado superficial de mortero. Los trabajos arqueológicos que se realizaron en la plaza del Ángel revelaron que la altura del lienzo era de $8 \mathrm{~m}$ de cortina, alcanzando 9,8 $\mathrm{m}$ con el remate almenado (Pascual y Martí 2002: 300). Sobre este recinto se añadieron otras estructuras: sobre el flanco sur se dispuso un forro exterior de mortero de 1,2 $\mathrm{m}$ y algunas esquinas de las torres se reforzaron con tapial de tierra calicostrada. En el siglo XII se agregó a todo el perímetro el antemuro y otra estructura de tapial, costra de mortero y relleno interior de tierra compactada. La anchura variaba entre 1,8 y 2,2 m. En la base del parapeto existían orificios que lo atravesaban, inclinados hacia el exterior, que se han interpretado como lanceras. La anchura de la liza entre la muralla y el antemuro también es variable, lo hace entre 2,8 y $4,5 \mathrm{~m}$, pero a la altura de las torres llega a ser menor de $1 \mathrm{~m}$ (Arraiz y Andújar 2010). En los tramos de la muralla localizados en la torre del Ángel y en el solar número 2 de la calle Blanquerías, ambos del siglo XI, se han realizado análisis granulométricos y mediciones. Los agujales de la torre del Ángel tienen una separación $1,1 \mathrm{~m}$ y una sección de $0,8 \times 0,3 \mathrm{~cm}$, tapieras de $1,12 \mathrm{~m}$ de longitud y $0,90 \mathrm{~m}$ de anchura y una modulación de palmo de 22,5-24 cm y codo mamuni de $47 \mathrm{~cm}$ (Martínez 2014: 38). Por su parte, en la calle Blanquerías se documentaron los restos de una torre semicircular y un tramo de muralla de $20 \mathrm{~m}$ de longitud y $10 \mathrm{~m}$ de altura hasta las almenas. Estas tenían un tamaño de $95 \times 95$ $\mathrm{cm}$ y $50 \mathrm{~cm}$ de grosor. En la intervención arqueológica también se excavó el antemuro que corría paralelo a la muralla, a 4,3 m de la misma. Estaba construida con tapia de mortero de cal y sus medidas variaban entre 1,1 y 0,78 m (Máñez y Bueso 2010: 177).

En Alzira la superficie intramuros, sin incluir la alcazaba, es de 8 ha, por tanto es superior a la de Burriana, de 3,6 ha. Ambas ciudades tienen un perímetro amurallado de morfología casi circular, que aparece ordenado por dos ejes viarios transversales. La madīna al-ğazīra debió su pujanza económica al comercio de la madera que se traía desde tierras de interior por el río Xúquer, además debió ser un punto estratégico fronterizo entre las coras de Tudmir al sur y la Balansiya al norte. Sabemos que fue objeto de combates en el año 928 (Soler 2002: 55, 60). Se hace mención a la muralla del siglo $\mathrm{XI}$ en las crónicas de la época, pero hay poca información sobre el recinto fortificado, las publicaciones solo describen que la técnica constructiva es de encofrado de piedras y mortero de cal con cajones de $2,3 \mathrm{~m}$ de longitud, 2,3 $\mathrm{m}$ de ancho y una altura de $0,85 \mathrm{~m}$. También tiene adosadas torres semicirculares de diámetro irregular que se han fechado entre los siglos XI y XIII (Ferrer 2002: 75-79).

Por su parte, como se ha apuntado en los apartados precedentes, las estructuras defensivas que configuran el 
recinto amurallado de Burriana presentan un alto grado de homogeneidad. El estudio de los muros lo determina en este sentido. El primer elemento a destacar es la tapia de tierra de la muralla, que muestra tongadas muy compactadas de aproximadamente $9 \mathrm{~cm}$ en cada cajón. Dentro de este contexto constructivo, difiere la composición de la arcilla y algunos tramos presentan tongadas de mortero de cal. Lo cierto es que estos tapiales incorporan ciertos aditivos en beneficio de la calidad de la fábrica, entre ellos áridos, conglomerantes y revestimientos de cal. Se trata de un método que sabemos que se empieza a generalizar en el siglo XI. La lista de paralelos para esta fábrica es larga, pero referiremos dentro de la región los tapiales del Castell Vell (Benedito y Llorens 2009-2010; García y Palmer 2018), Onda (Navarro y Estall 2011), Denia (Azuar 1989) y fuera de la región valenciana los del siglo XI e inicios del siglo XII de contextos sevillanos (Graciani y Tabales 2008: 140-143), entre otros. Sin embargo, en este mismo contexto sevillano, J. Canivell y A. Graciani (2015: 14) describen que el calicostrado está presente pero especialmente en las fábricas árabes de época nazarí, cuando se hizo más común. Asimismo, en Burriana algunos tramos del recinto conservan verdugadas o marlotas en el encuentro entre cajones que consistían en una tongada de cal, sistema que se ha datado en la zona sevillana a partir de la época almohade (Graciani y Tabales 2008: 140).

Otro elemento a destacar está relacionado con la cimentación de la muralla que se excavó en la calle Mayor, que se puede poner en relación con la técnica documentada en Murcia entre los siglos X y XII, con el basamento enterrado y los alzados de tapia de tierra (Navarro y Jiménez 2011: 88). Los cimientos solían estar dispuestos sobre el nivel de suelo conformando un zócalo; su construcción no se hacía excavando en la tierra, sino que se levantaban sobre un suelo provisional de trabajo, para a continuación elevarlos. El aplomado del muro se consigue con esta técnica constructiva debido a la presencia en la cota inferior de dichos cimientos de suelos de trabajo y la existencia de enlucidos preparatorios por debajo de las cotas de los suelos definitivos. En Guardamar del Segura (Alicante) los hallazgos han puesto de manifiesto la existencia de una fase de fines del siglo X y principios del XI que se caracteriza por la generalización de la tapia de tierra sobre basamentos de mampostería (Navarro y Jiménez 2011: 88-94).

Respecto a los patrones de medida de los cajones, se ha propuesto la existencia de diferentes módulos definidos por su altura. Por un lado, el tapial de módulo bajo, que presenta una altura inferior o igual a $80 \mathrm{~cm}$, se ha vinculado al codo rassasí de 58,93 cm, en el ámbito omeya; mientras que el tapial de módulo alto, que oscila entre 85 y $95 \mathrm{~cm}$, estaría asociado probablemente con derivaciones de la equivalencia de dos codos mamunies, de 47,14 cm cada uno. En el Castell Vell de Castellón se conocen las dimensiones de algunas tapiadas, ya fueran de tierra o mampostería. Por regla general, la altura se sitúa alrededor de los $82 \mathrm{~cm}$, mientras que la anchura oscila entre $1,1 \mathrm{~m}$ en las murallas y $47 \mathrm{~cm}$ en algunos muros interiores (Benedito y Llorens 2009-2010: 182; García y Palmer 2018: 92). En Alcalà de Xivert las tapiadas poseen una altura de $80 \mathrm{~cm}$ mientras que se alternan diferentes largos, de 1,45 a 4,10 m (Hofbauerová y De Antonio 2001: 78). Fuera de esta región, en el territorio sevillano, desde la segunda mitad del siglo XII se han fechado encofrados en los que se ha comprobado un aumento del módulo de la tapia. Por otro lado, en las fábricas mixtas los tapiales de módulo alto proliferan independientemente de su tipología y composición (Graciani y Tabales 2008: 137). El espesor del muro también es variable y abarca desde 1,15 hasta casi $3 \mathrm{~m}$. En general, en las torres sevillanas se emplean espesores menores que varían de 1 a 1,5 m (2-3 codos mamunies), dependiendo de la planta. Siguiendo estas equivalencias, la fábrica clásica de tapia almohade sevillana se trata de una estructura monolítica en lienzos y verdugada en torres, mientras que los cajones tienden a ser bajos, entre 80 y $85 \mathrm{~cm}$ (Canivell y Graciani 2015: 15-18).

Por otro lado, en lo referente al estudio, documentación y datación de los restos arquitectónicos, los antemuros se han confirmado en la arquitectura hispanomusulmana a partir de mediados del siglo XI. Su construcción se ha puesto en relación con la mejora de las estructuras defensivas ya existentes y las obras de nueva construcción (Pascual y Martí 2002; Arraiz y Andújar 2010; Gómez 2017: 136). De las torres terraplenadas de Burriana se han encontrado paralelos de similares características en Valencia, pero del siglo XII (Pascual y Martí 2002: 298; Arraiz y Andújar 2010). Por su parte, en Murcia a partir de finales del siglo XI y principios del XII las torres se caracterizan por utilizar tapia de hormigón como cimiento y zócalo (Navarro y Jiménez 2011: 87). El cuerpo superior de las torres de Burriana era de tapial verdugado, técnica que se ha fechado en la zona sevillana a partir de época almohade (Graciani y Tabales 2008: 136). En la torre de la calle San Pascual debido a la pérdida de parte de la calicostra, se sabe que las verdugadas delimitaban cajones de unos $90 \mathrm{~cm}$. En 
cuanto a la unión de las torres con la muralla de esta ciudad, en ausencia de datos definitorios, el ejemplo mejor conservado corresponde también al hallazgo de la calle San Pascual, aunque la mayor parte del lienzo fue derruido. En Sevilla se han registrado torres de tapia que se adosan al lienzo desde las primeras hiladas, sin embargo, del quinto hilo para arriba se alternan hiladas trabadas y adosadas; mientras que en otras torres desde época taifa se ha observado un planteamiento similar, en el que estas y los lienzos se erigen como bloques adosados, hasta que se traban en las hiladas superiores (Márquez 2018: 16). La torre del Racó de l'Abadia de Burriana fue construida mediante la yuxtaposición de tapiales de mortero y posteriormente, no sabemos cuándo, rematada con ladrillos. Los ladrillos se utilizan en Al-Ándalus sobre todo a partir de la segunda mitad del siglo XII. Los almorávides y, sobre todo, los almohades estandarizarán estos procesos, lo que muchas veces ha dificultado la diferenciación constructiva entre ambos periodos, erigiendo torres en las que se combinarán encofrados masivos para las partes macizas y otros modulares para las cámaras (Navarro y Jiménez 2011: 102; Márquez 2018: 30).

A modo de conclusión, la fecha de la estructura defensiva de la madīna Buryāna podría situarse entre mediados del siglo XI y principios del XII. Pese a la dificultad que entraña la ausencia de datos sobre la fecha de construcción de dicho muro, probablemente no se puede retrotraer con anterioridad a esta centuria. No se han documentado por el momento fases constructivas anteriores a esta época. El recinto es más tardío que las murallas de Valencia o Alzira probablemente porque debió tener escaso interés estratégico durante los primeros siglos de dominio musulmán. En este sentido, los documentos cristianos más antiguos hacen referencia al alto valor estratégico de Burriana probablemente como lugar de control del paso del río Millars a lo largo de la vía que unía Tortosa y Valencia precisamente a partir de los siglos XI y XII. De ello se desprende que la cerca no comenzaría a levantarse en el momento de la fundación de la ciudad. El poblamiento de época islámica, en función de los datos que ofrecen los textos árabes (Lévi Provençal 1953: 72) y la cultura material hallada en las excavaciones, se podría situar en el siglo $\mathrm{X}$ y aunque pudo haber un primer recinto de época islámica, no hay ninguna prueba de ello. Los portales retranqueados con posterioridad fueron sustituidos por puertas alineadas con las calles actuales, como lo atestigua la aparición de restos de la cimentación de la muralla y el antemuro bajo el firme de la calle Mayor. No se ha encontrado documentación que feche estas reformas, que quizá se produjeron entre los siglos XVII y XVIII, y quizá a principios del siglo XVIII, con el decreto de Felipe V, se inició el proceso de derribo.

El desmoronamiento definitivo de la cerca defensiva y de las torres se debió dar a finales del siglo XIX, pues durante las guerras carlistas la ciudad de Burriana sufrió de nuevo episodios de asedio, lo que probablemente llevó a la recuperación de algunos tramos de la muralla y portales. Tras esta contienda se debió precipitar el total derribo de puertas y el desplome de buena parte del lienzo de la muralla, construyéndose sobre sus cimientos a partir de este momento y sobre todo durante la centuria siguiente otras paredes más estrechas de mampostería de tierra, cantos rodados y ladrillos.

\section{BIBLIOGRAFÍA}

Arquer, N. y Falomir, F. 2008: "El Castell de Xivert (Alcalà de Xivert, Baix Maestrat). Campanyes d'excavació 2007 i 2008. Primeres valoracions", Quaderns de Prehistòria i Arqueologia de Castelló, 26, pp. 207-210.

Arraiz García, N. y Andújar Alba, A. (coords.) 2010: Guía de Arquitectura de Valencia. Colegio Territorial de Arquitectos de Valencia, Valencia.

Azuar Ruiz, R. 1989: Denia islámica, arqueología y poblamiento. Instituto Alicantino de Cultura Juan Gil-Albert, Alicante.

Bazzana, A. 1976: "Problemes d'architecture militaire au Levant espagnol: le chateau d'Alcalá de Chivert", actas VIII Colloque International (BadMünstereifel, 1976), Château-Gaillard. Études de castellologie médiévale, pp. 21-46. Caen.

Bazzana, A.; Cressier, P. y Guichard, P. 1988: Les châteaux ruraux d'AlAndalus histoire et archéologie des 'husun' du sud-est de l'Espagne. Collection de la Casa de Velázquez, 19, Madrid.

Benedito Nuez, J. y Llorens Otero, J. M. 2009-2010: “La arqueología del Castell Vell de Castellón de la Plana”, Castillos de España, 156-159, pp. 179-183.

Canivell, J. y Graciani, A. 2015: “Caracterización constructiva de las fábricas de tapia en las fortificaciones almohades del antiguo Reino de Sevilla", Arqueología de la Arquitectura, 12, pp. 1-22. https://doi.org/10.3989/arq. arqt.2015.003

De María, R. 1933: El repartiment de Burriana y Villarreal. Caja Rural Católico-Agraria S. Coop. de Crédito, Ltda., Vila-real.

Edrîsî. 1968: Description de l'Afrique et de l'Espagne. Edición y traducción R. Dozy et M. J. de Goeje, Leiden, Brill, 1866, reimpresión anastática 1968.

Felip, V. 1991: "La conquesta de Borriana al Llibre dels Fets", en N. Mesado (dir.), Burriana en su Historia, II, pp. 49-68. Ayuntamiento de Burriana, Burriana.

Ferrer Clarí, A. 2002: "Les muralles d'Alzira, escut de la ciutat i clau del Xúquer”, en A. Furió y J. Aparici (coords.), Castells, torres i fortificacions en la Ribera del Xúquer, pp. 75-88. Universitat de València, Valencia.

García, V. 1989: Llibre de privilegis de Borriana (1233-1350). Col·lecció Papers 14, Burriana.

García Borja, P. y Palmer Broch, J. E. (eds.) 2018: El Castell Vell de Castelló. Recuperant el patrimoni, reconstruint la historia. Castellón.

Gómez Sahuquillo, M. 2017: Castellología islámica de la Ribera del Xúquer (Valencia). Tesis Doctoral inédita, UNED, Madrid.

Graciani García, A. y Tabales Rodríguez, M. A. 2008: "El tapial en el área sevillana. Avance cronotipológico estructural”, Arqueología de la Arquitectura, 5, pp. 135-158. https://doi.org/10.3989/arq.arqt.2008.93 
Guichard, P. 1987: "Los orígenes islámicos", en N. Mesado (dir.), Burriana en su historia, I, pp. 71-87. Ajuntament de Borriana, Burriana.

Guichard, P. 2001: Al-Andalus frente a la conquista cristiana: los musulmanes de Valencia, siglos XI-XIII. Universitat de València, Valencia.

Guichard, P. y Mesado, N. 1976. Un menut poble del País Valencià durant l'època musulmana: Borriana. Col·lecció Papers 1, Burriana.

Gurriarán Daza, P. y Sáez Rodríguez, A. J. 2002: “Tapial o fábricas encofradas en recintos urbanos andalusíes", en actas II Congreso Internacional "La Ciudad en Al-Andalus y el Magreb", pp. 561-625, Fundación El Legado Andalusí, Granada.

Hofbauerová, V. y De Antonio, J. M. 2001: “Consolidación y restauración del muro de Alafia. Castillo de Xivert (Castellón)", Loggia: Arquitectura y restauración, 11, pp. 74-85. https://doi.org/10.4995/loggia.2001.5232

Al-Idrīsī 1989: Los caminos de al-Andalus en el siglo XII. Edición y traducción J. A. Mizal. CSIC, Madrid.

Labarta, A.; Barceló, C. y Veglison, J. 2011: València àrab en prosa $i$ vers. Publicacions de la Universitat de València, Valencia.

Lévi Provençal, É. 1953: “La description de l'Espagne d'Ahmad al-Râzî. Essai de reconstitution de l'original arabe et traduction française", $\mathrm{Al}$ Andalus, XVIII, pp. 51-108.

Llibre del repartiment del Regne de Valencia 1979: Edición, estudio preliminar e índices M. ${ }^{\mathrm{a}}$ D. Cabanes Pecourt y R. Ferrer Navarro, 2 vols. Anúbar, Zaragoza.

Máñez J. y Bueso, V. 2010: "Excavación arqueológica, restauración y exposición en el edificio de la calle Blanquerías $\mathrm{n}^{\circ} 2$ - Rocas $\mathrm{n}^{\circ} 8$ de Valencia", en Actes de les III Jornades d'Aqueologia de València i Castelló, pp. 173-182. Ayuntamiento de Valencia, Valencia.

Márquez Bueno, S. 2018: "La tecnología constructiva andalusí: obra encofrada y revestimientos en la arquitectura militar (ss. XI-XIII). El ejemplo de las torres", Arqueología de la Arquitectura, 15, pp. 1-33. https://doi. org/10.3989/arq.arqt.2018.007

Martínez Talón, T. 2014: Estudio y puesta en valor sur del tramo de muralla islámica de la Plaza del Ángel de Valencia. Diagnóstico y tratamiento. Trabajo Final de Máster, Universidad Politécnica de Valencia, Valencia.

Melchor, J. M. 2009: "Intervención arqueológica en el entorno del ábside" en El Arte de Restaurar el Patrimonio. La Llum de les Imatges (Borriana, Vila-real, Castelló, 2008-2009), pp. 99-115. Fundació La Llum de les Imatges, Valencia.

Melchor, J. M. 2009-2010: "Nuevas aportaciones al conocimiento de la muralla islámica de Burriana", Castillos de España, 156-159, pp. 135-138.
Melchor, J. M. 2011: "La arqueología como fuente de estudio para la Burriana medieval”, en J.M. Melchor, J. Benedito y T. Pasíes (eds.), La arqueología de la Buriyyana islámica a la Borriana cristiana, pp. 11-47. Ajuntament de Borriana, Borriana.

Melchor, J. M. 2013: Diez años del Servicio Municipal de Arqueología de Burriana (2003-2013). Ajuntament de Borriana, Burriana.

Mesado, N. 1991: "La muralla y sus portales", en N. Mesado (dir.), Burriana en su Historia, II, pp. 69-88. Ajuntament de Borriana, Burriana.

Navarro Palazón, J. y Estall Poles, V. 2011: "Huellas del pasado. La alcazaba de Onda", El legado Andalusí, 44, pp. 74-83.

Navarro Palazón, J. y Jiménez Castillo, P. 2011: "Materiales y técnicas constructivas en la Murcia andalusí (siglos X-XIII)", Arqueología de la Arquitectura, 8, pp. 85-120. https://doi.org/10.3989/arqarqt.2011.10012

Palomar Macián, V. y Berga Pérez, A. 2005: Rehabilitación del patrimonio histórico y urbano del casco antiguo de Segorbe (1999-2004). Ayuntamiento de Segorbe, Segorbe.

Pascual, J. y Martí, J. 2002: "El recinto fortificado de la Valencia musulmana", en I. C. Fernandes Ferreira (coord.), Mil annos de fortificações na Península Ibérica e no Magreb (500-1500), Actas do Simpósio Internacional sobre Castelos 2000, pp. 291-309. Edições Colibrí y Câmara Municipal de Palmela, Lisboa.

Ramón Fernández, F. 2001: El ingreso en la comunidad de pescadores de El Palmar y la transmisión hereditaria del "redoli". Publicacions de la Universitat de València, Valencia.

Roca y Alcaide, F. 1932: Historia de Burriana. Establecimiento tipográfico hijo de J. Armengot, Castellón.

Soler Molina, A. 2002: "Alzira del Xúquer: gènesi urbana i urbanisme planificat a la cora andalusina de València (segle IX)", en A. Furió y J. Aparici (coords.), Castells, torres i fortificacions en la Ribera del Xuquer, pp. 5174. Universitat de València, Valencia.

Ulloa, P. 2000: "Excavación Arqueológica en la Iglesia del Salvador de Burriana”, en N. Mesado, y J. L1. Gil (coords.), XXX Aniversari del Museu Arqueologic Comarcal de la Plana Baixa: Burriana (1967-1997). Col·lecció Papers 20, Burriana.

Vallvé Bermejo, JJ. 1986: La división territorial de la España musulmana. CSIC-Instituto de Filología, Departamento de Estudios Árabes, Madrid.

Verdegal, V. 1989: "Excavacions arqueològiques d'urgència a Borriana: la construcció defensiva medieval", Butlletí de l'Associació Arqueològica de Castelló, Llansol de Romaní, 6-7, pp. 56-60.

Viciana, R. M. de. 1564: Libro tercero de la Crónica de la ínclita y coronada ciudad de Valencia y de su reino. Editado por Joan Iborra, 2002. Universidad de Valencia, Valencia. 